\title{
Superconducting Technology Program Sandia 1996 Annual Report
}

\author{
E. Peter Roth
}

\section{Prepared by}

Sandia National Laboratories

Albuquerque, New Mexico 87185 and Livermore, California 94550

for the United States Department of Energy

under Contract DE-AC04-94AL85000

Approved for pubblic release; distribution is unlimited.
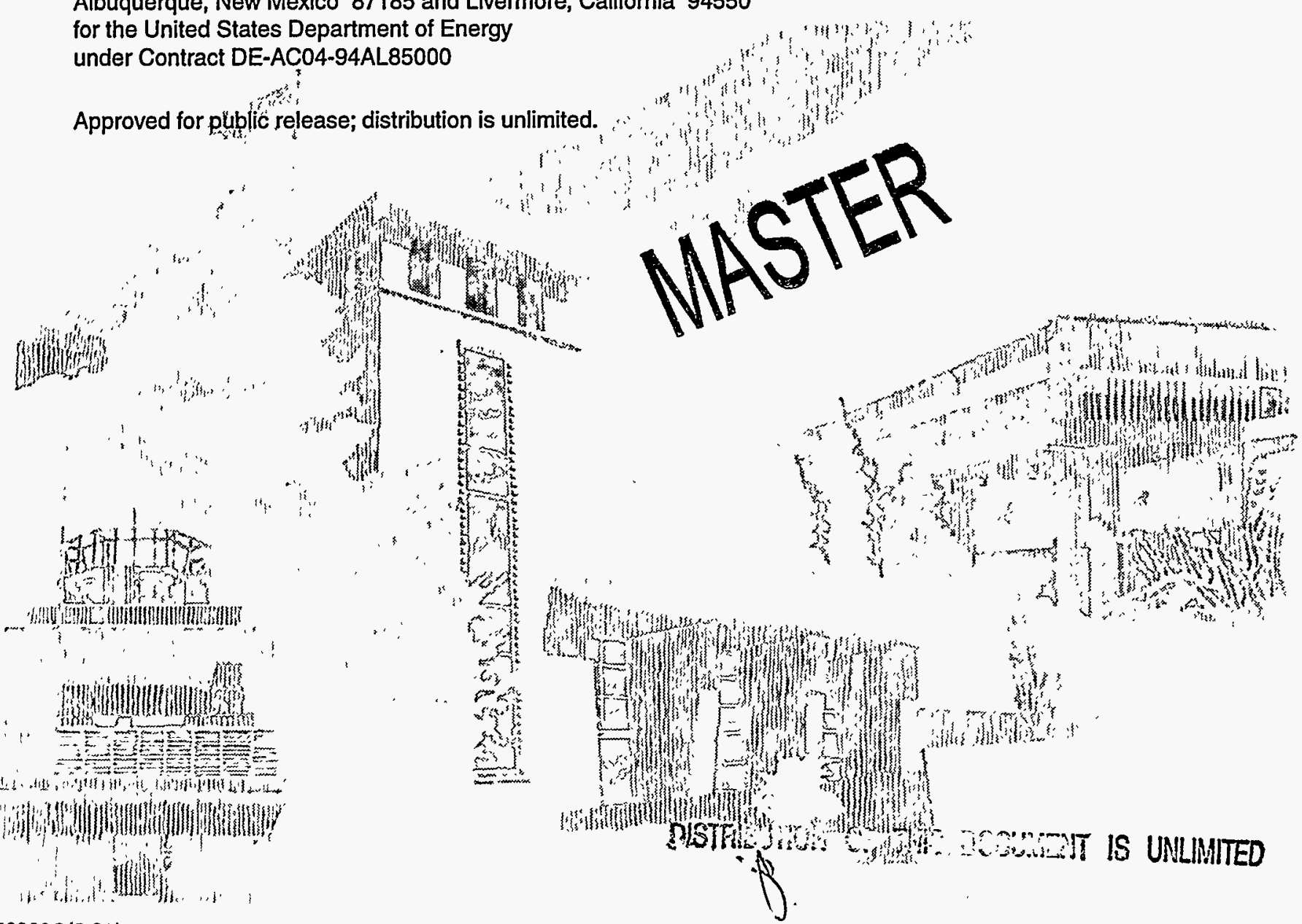
Issued by Sandia National Laboratories, operated for the United States Department of Energy by Sandia Corporation, a Lockheed Martin Company.

NOTICE: This report was prepared as an account of work sponsored by an agency of the United States Govemment. Neither the United States Government nor any agency thereof, nor any of their employees, nor any of their contractors, subcontractors, or their employees, makes any warranty, express or implied, or assumes any legal liability or responsibility for the accuracy, completeness, or usefulness of any information, apparatus, product, or process disciosed, or represents that its use would not infringe privately owned rights. Reference herein to any specific commercial product, process, or service by trade name, trademark, manufacturer, or otherwise, does not necessarily constitute or imply its endorsement, recommendation, or favoring by the United States Government, any agency thereof or any of their contractors or subcontractors. The views and opinions expressed herein do not necessarily state or reflect those of the United States Government, any agency thereof or any of their contractors.

Printed in the United States of America. This report has been reproduced directly from the best available copy.

Available to DOE and DOE contractors from

Office of Scientific and Technical Information

PO Box 62

Oak Ridge, TN 37831

Prices available from (615) 576-8401, FTS 626-8401

Available to the public from

National Technical Information Service

US Department of Commerce

5285 Port Royal Rd

Springfield, VA 22161

NTIS price codes

Printed copy: A03

Microfiche copy: A0I 


\section{DISCLAIMER}

Portions of this document may be illegible in electronic image products. Images are produced from the best available original document. 
SAND97-0328

Unlimited Release

Printed February 1997

Category UC-1390

\title{
Superconducting Technology Program \\ Sandia 1996 Annual Report
}

\author{
Report prepared by \\ E. Peter Roth \\ Photovoltaic System Components Dept. \\ Sandia National Laboratories \\ P.O. Box 5800 \\ Albuquerque, NM 87185-0752 \\ This report has been prepared for the \\ Advanced Utility Concepts Division \\ Office of Energy Management \\ Energy Efficiency \& Renewable Energy \\ U.S. Department of Energy
}

\begin{abstract}
Sandia's Superconductivity Technology Program is a thallium-based high-temperature superconductor (HTS) research and development program consisting of efforts in powder synthesis and process development, open-system thick film conductor development, wire and tape fabrication, and HTS motor design. The objective of this work is to develop high-temperature superconducting conductors (wire and tape) capable of meeting requirements for high-power electrical devices of interest to industry. The research efforts currently underway are: 1) Process development and characterization of thallium-based high-temperature superconducting closed system wire and tape, 2) Investigation of the synthesis and processing of thallium-based thick films using two-zone.processing, and 3) Cryogenic design of a $30 \mathrm{~K}$ superconducting motor. This report outlines the research that has been performed during FY96 in each of these areas.
\end{abstract}




\section{CONTENTS}

1 Growth of Thick(TI,Pb)-(Sr,Ba)-Ca-Cu-O Superconducting Films Using a Controlled Tl-Oxide Source ......................... 1-1

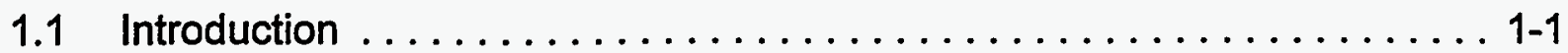

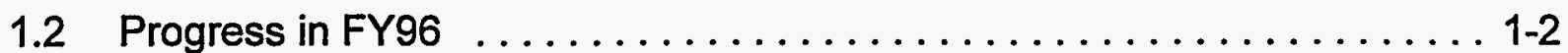

1.2.1 Microstructural Development in $\mathrm{Tl}_{1} \mathrm{Ba}_{2} \mathrm{Ca}_{2} \mathrm{Cu}_{3} \mathrm{O}_{x}$ and $\mathrm{Pb}$-, $\mathrm{Sr}$-doped

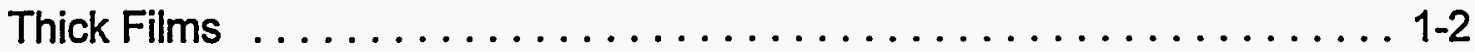

1.2.2 Transient Temperature Processing of (Pb,Sr)-doped Tl-1223 Films in a

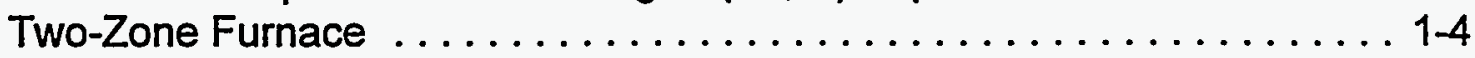

1.2.3 Transient Atmosphere Processing of ( $\mathrm{Pb}, \mathrm{Sr})$-doped Tl-1223 Films in a Two-Zone Furnace . . . . . . . . . . . . . . . . . . . . . . . 1-5

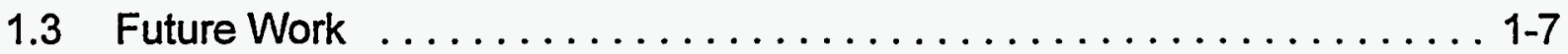

2 Processing of Powder-in-Tube TI-1223 Tapes $\ldots \ldots \ldots \ldots \ldots \ldots \ldots \ldots \ldots \ldots \ldots \ldots$

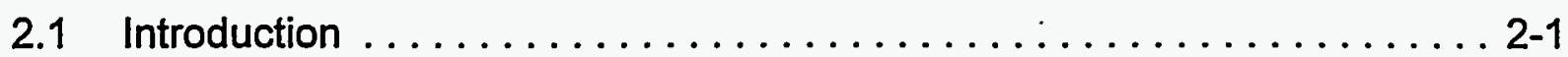

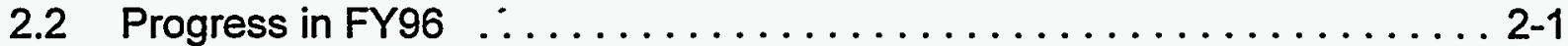

2.2.1 Pull-Through Temperature/Atmosphere Gradient Furnace Processing . . . 2-1

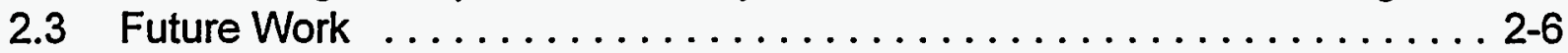

3 Process Research on the Synthesis of High-Temperature Superconductors 3-1

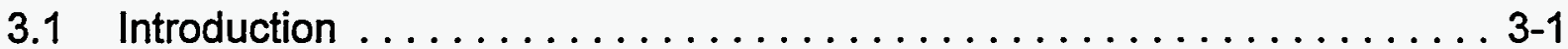

3.2 Progress in FY96 $\ldots \ldots \ldots \ldots \ldots \ldots \ldots \ldots \ldots \ldots \ldots \ldots \ldots .1$

3.1.1 Quench Studies of Microstructural Development in TI-1223 Tapes with Varying Sr/Ba Ratios . . . . . . . . . . . . . . . . . .

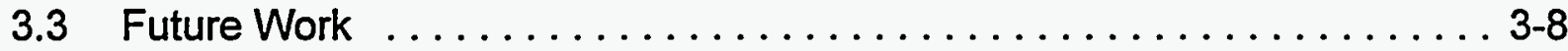

4 Effects of Fluxing Agents on Microstructural Development of TI-1223 . . . . . . 4-1

4.1 Introduction ................................ 4-1

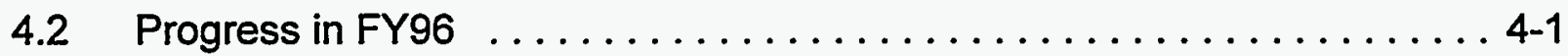

4.2.1 TIF substitution for $\mathrm{Tl}_{2} \mathrm{O}_{3}$ in $\left(\mathrm{TI}_{0.5} \mathrm{~Pb}_{0.5}\right)\left(\mathrm{Sr}_{0.8} \mathrm{Ba}_{0.2}\right)_{2} \mathrm{Ca}_{2} \mathrm{Cu}_{3} \mathrm{O}_{x}$ and $\mathrm{Tl}_{1} \mathrm{Ba}_{2} \mathrm{Ca}_{2} \mathrm{Cu}_{3} \mathrm{O}_{\mathrm{x}}$ compositions. . . . . . . . .

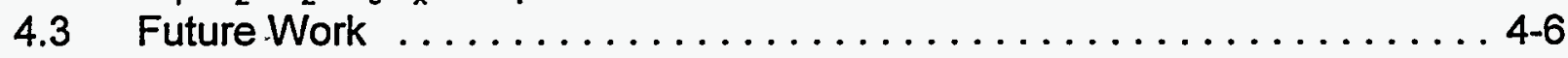


5 Cryogenic Design of a High-Temperature Superconducting (HTS) Motor . . . . . 5-1

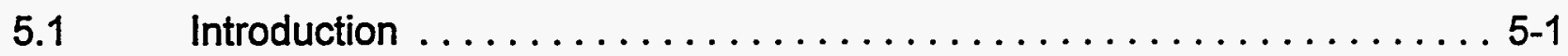

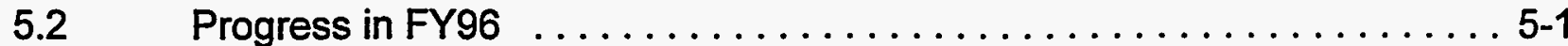

5.3

Future Work

$5-2$ 


\section{FIGURES}

1-1. $\left(\mathrm{TI}_{0.5} \mathrm{~Pb}_{0.5}\right)\left(\mathrm{Sr}_{0.8} \mathrm{Ba}_{0.2}\right)_{2} \mathrm{Ca}_{2} \mathrm{Cu}_{3} \mathrm{O}_{\mathrm{x}}+5 \mathrm{wt} \% \mathrm{Ag} ; 500 \mathrm{x} \ldots \ldots \ldots \ldots \ldots \ldots \ldots \ldots \ldots \ldots . .3$

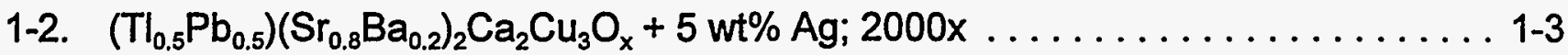

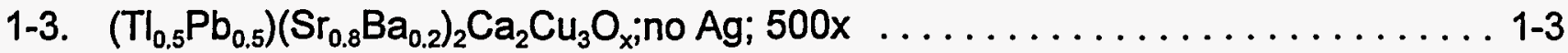

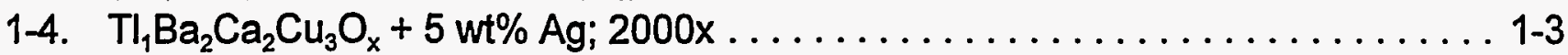

1-5. Temperature profile of transient-temperature two-zone run. . . . . . . . . . 1-4

1-6. Schematic of transient-atmosphere two-zone furnace. . . . . . . . . . . . . 1-5

1-7. Temperature profile of transient-atmosphere run in two-zone furnace. . . . . . 1-6

1-8. Critical currents for low $\mathrm{pO}_{2}$ induced transient melt processed films. . . . . . . . 1-7

2-1. Pull-Through Temperature/Atmosphere Gradient Furnace. . . . . . . . . . 2-3

2-2. SEM collage of $\mathrm{Sr}_{1.6} \mathrm{Ba}_{0.4}$ Tl-1223 block grain structure after pull-through

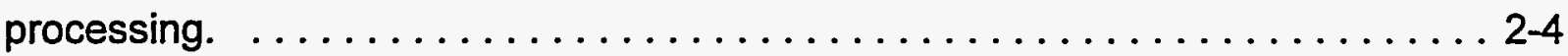

2-3. SEM micrograph of $\mathrm{Sr}_{0.8} \mathrm{Ba}_{1.2}$ composition tape processed in pull-through furnace. 2-4

3-1. Thermal schedule for quench experiments. . . . . . . . . . . . . . 3-2

3-2. SEM micrographs showing collage pictures of quenched tape microstructures. . . 3-3

3-3. Microstructural development of TI-1223/TI-1212 from the melt regime. . . . . . . 3-4

3-4. Melt decomposition of the TI-1223 microstructure. . . . . . . . . . . . 3-5

3-5. Developing microstructure of $\mathrm{Tl}_{2} \mathrm{O}_{3}$ based core at $880^{\circ} \mathrm{C} \ldots \ldots \ldots \ldots \ldots$ 3-6

3-6. Developing microstructure of $\mathrm{Tl}_{2} \mathrm{O}_{3} / \mathrm{TIF}$ based core at $880^{\circ} \mathrm{C} \ldots \ldots \ldots \ldots \ldots$ 3-6

3-7. Time development of $\mathrm{Tl}_{2} \mathrm{O}_{3} \mathrm{TIF}$ containing core at $880^{\circ} \mathrm{C} \ldots \ldots \ldots \ldots \ldots \ldots$ 3-7

4-1. $\mathrm{Tl}_{1} \mathrm{Ba}_{2} \mathrm{Ca}_{2} \mathrm{Cu}_{3} \mathrm{O}_{\mathrm{x}}+5 \mathrm{wt} \% \mathrm{Ag}$ : sealed Au pouch. ................ 4-3

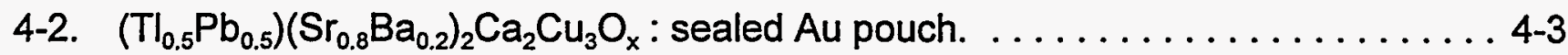

4-3. $\left(\mathrm{TI}_{0.5} \mathrm{~Pb}_{0.5}\right)\left(\mathrm{Sr}_{0.8} \mathrm{Ba}_{0.2}\right)_{2} \mathrm{Ca}_{2} \mathrm{Cu}_{3} \mathrm{O}_{\mathrm{x}}+5 \mathrm{wt} \%$ Ag: sealed Au pouch. . . . . . . . 4-3

4-4 CBC-14 (undoped + Ag); TIF/precursor pellet; $860^{\circ} \mathrm{C} / \mathrm{O}_{2} / \mathrm{Au}$ pouch; $500 \mathrm{x}$. . . . . . 4-4

4-5. CBC-6 (Pb-,Sr-doped + Ag); TIF/precursor pellet; $860^{\circ} \mathrm{C} / \mathrm{O}_{2} / \mathrm{Au}$ pouch; $2000 \mathrm{x}$. . . 4-4

4-6. Non-Ag containing precursor. $\mathrm{CBC}-10$; $\mathrm{Pb}-$,Sr-doped; $\mathrm{CBC}-17$ undoped.

TIF coated pellets, $860^{\circ} \mathrm{C}$, open furnace. . . . . . . . . . . . . .

4-7. 5wt\% Ag containing precursor. CBC-6; Pb-,Sr-doped; CBC-14; undoped TIF coated pellets, $860^{\circ} \mathrm{C}$, open furnace. 


\section{TABLES}

2-1. Temperature/Atmosphere Gradient Furnace Processing. ........... 2-5

4-1. Phases and \% conversion; TIF coated pellets sealed in Au pouch under $\mathrm{O}_{2} \ldots$. . 4-2

4-2. Phases and $\%$ conversion; TIF coated pellets; $860^{\circ} \mathrm{C}$ /open furnace $/ \mathrm{O}_{2} \ldots \ldots .4-5$ 


\section{CONTRIBUTORS}

\section{Sandia Contributors to the \\ Superconducting Technology Program \\ for Electric Energy Systems}

\section{Program Manager}

E. Peter Roth

Ceramic Synthesis

James A. Voigt

Diana L. Lamppa

Ceramic Processing

Steve Lockwood

Advanced Materials/Magnetic

Characteization

Eugene L. Venturini

Superconducting Materials/Transport

Properties

Frank Chavez

Thermal \& Fluid Modeling

Ronald C. Dykhuizen 
1 Growth of Thick(TI,Pb)-(Sr,Ba)-Ca-Cu-O Superconducting Films Using a Controlled TI-Oxide Source

\subsection{Introduction}

The objective of this project is to develop high-temperature superconducting wire capable of meeting the requirements for high-power electrical devices of interest to industry. Primary interest has been to develop materials and processes which can lead to the practical production of wires which can carry high currents in the presence of typical operating magnetic fields at liquid nitrogen temperature or higher, although lower temperature operation is considered for special applications. The thalliumbased single layer system is considered one of the most viable materials for operation in moderate magnetic fields at $77 \mathrm{~K}$. In particular, the $\mathrm{Pb}$ - and Sr-substituted system is believed to have the best performance in magnetic field (high irreversibiltiy line) and most readily results in the desired TI-1223 phase.

Conductors have been classified as either- "closed system" conductors, usually produced by the powder-in-tube (PIT) technique, or as "open system" conductors. "Open" system conductors consist of a flexible substrate, usually metallic, on which the superconductor precursor powder is deposited by any of a number of techniques and then thallinated to produce the final superconducting film. We use the "two-zone" technique for thallination where the sample is maintained at one temperature in a quartz tube while a $\mathrm{Tl}_{2} \mathrm{O}_{3}$ source in another portion of the tube is brought to a temperature sufficient to produce a $\mathrm{Tl}_{2} \mathrm{O}$ overpressure which is incorporated into the sample film. The advantage of this method is the ability to separately control sample temperature and thallium content during the critical formation stage of the superconducting grains. This method has been successful in producing thin film aligned TI-1223 microstructures with high $\mathrm{J}_{\mathrm{c}} \mathrm{s}$ and good performance in magnetic field. The present challenge is to produce thicker films with high current carrying capacity using deposition techniques that are easily scalable to long lengths. 


\subsection{Progress in FY96}

\subsubsection{Microstructural Development in $\mathrm{Tl}_{4} \mathrm{Ba}_{2} \mathrm{Ca}_{2} \mathrm{Cu}_{3} \mathrm{O}_{x}$ and $\mathrm{Pb}$-,Sr-doped Thick Films}

Two-zone processing of dip coated $\mathrm{Ag}$ films has been performed for both the undoped and the $\mathrm{Pb}$-,Sr-doped $\mathrm{Tl}_{1} \mathrm{Ba}_{2} \mathrm{Ca}_{2} \mathrm{Cu}_{3} \mathrm{O}_{x}$ precursor powders. The $\mathrm{Pb}$-,Sr-doped samples, $\left(\mathrm{TI}_{0.5} \mathrm{~Pb}_{0.5}\right)\left(\mathrm{Sr}_{0.8} \mathrm{Ba}_{0.2}\right)_{2} \mathrm{Ca}_{2} \mathrm{Cu}_{3} \mathrm{O}_{\mathrm{x}}$, were processed at $910^{\circ} \mathrm{C}$ while the undoped film was processed at $863^{\circ} \mathrm{C}$. Processing temperatures for the $\mathrm{Pb}-, \mathrm{Sr}$-doped compositions were typically in the range $910^{\circ} \mathrm{C}-920^{\circ} \mathrm{C}, 50^{\circ} \mathrm{C}$ higher than for the undoped films. Film thicknesses ranging from 10-100 $\mu \mathrm{m}$ were produced and processed in the two-zone furnace to achieve optimum thallium content. Critical currents of 14 amps were achieved in the undoped films while currents of only about 2.5 amps were seen in the $\mathrm{Pb}-, \mathrm{Sr}$-doped compositions. We have examined the microstructure of these films by SEM and XRD and have observed very different grain and phase development for the doped and undoped materials. Figures 1-1 and 1-2 show micrographs for the $\mathrm{Pb}-, \mathrm{Sr}$-doped films with $5 \mathrm{wt} \%$ added $\mathrm{Ag}$. The grain structure consisted of large, unaligned blocky grains with discrete secondary phases. The doped material without Ag, Figure 1-3, seemed to have a more homogeneous composition with fewer secondary phases. Figure 1-4 shows the microstructure of the undoped, Ag containing film. Comparison to the structure shown in Figure 1-2 shows that the undoped material has a much finer grain structure and porosity distributed on a finer scale. XRD of the doped films showed a background of unaligned TI-1212 grains which appeared in the SEM micrographs as small TI-1212 inclusions in the TI1223 grains. Apparently the addition of $\mathrm{Ag}$ to the $\mathrm{Pb}$-, Sr-doped precursors results in more bulk nucleation and enhanced, localized melting resulting in greater secondary phase formation. 


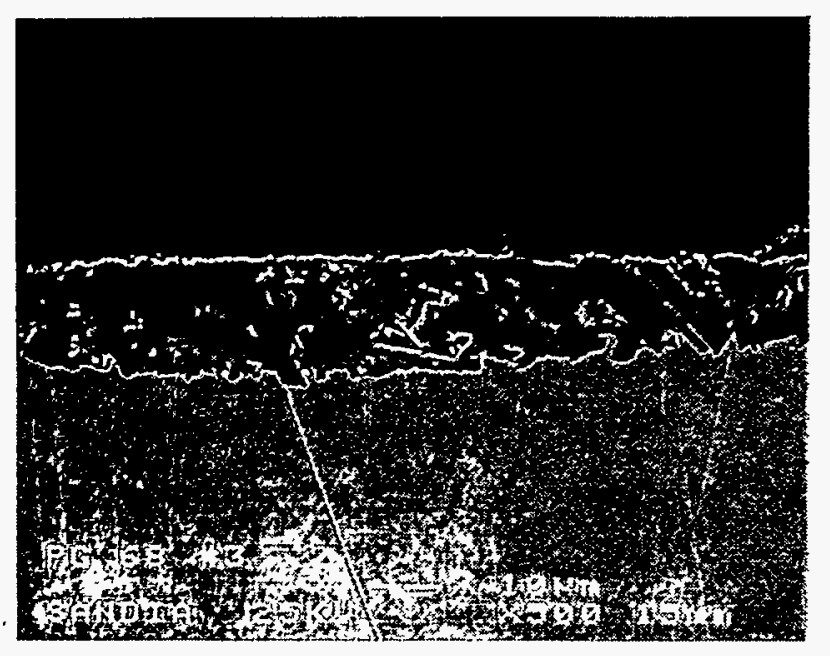

Figure 1-1. $\left(\mathrm{TI}_{0.5} \mathrm{~Pb}_{0.5}\right)\left(\mathrm{Sr}_{0.8} \mathrm{Ba}_{0.2}\right)_{2} \mathrm{Ca}_{2} \mathrm{Cu}_{3} \mathrm{O}_{x}$ $+5 \mathrm{wt} \% \mathrm{Ag} ; 500 \mathrm{x}$.

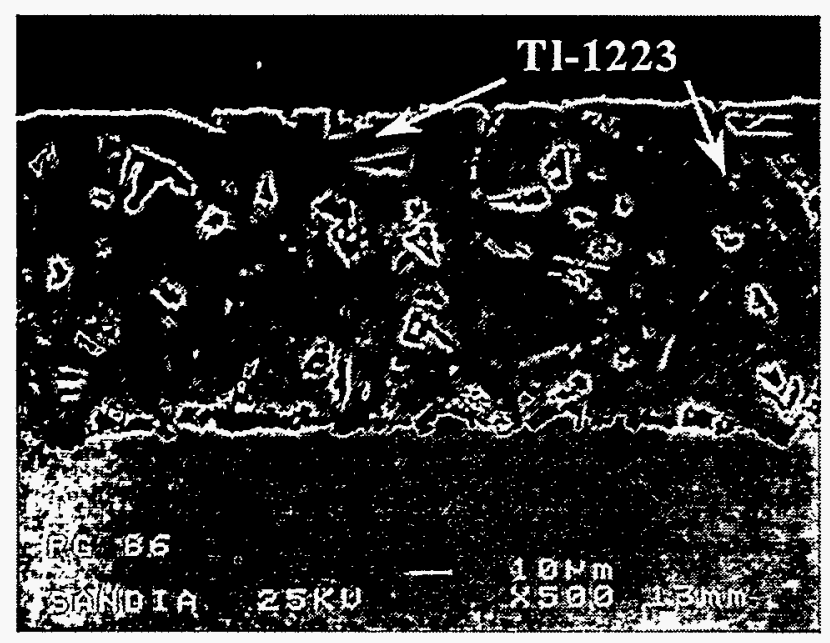

Figure 1-3. $\left(\mathrm{Tl}_{0.5} \mathrm{~Pb}_{0.5}\right)\left(\mathrm{Sr}_{0.8} \mathrm{Ba}_{0.2}\right)_{2} \mathrm{Ca}_{2} \mathrm{Cu}_{3} \mathrm{O}_{\mathrm{x}}$; no Ag; 500x.

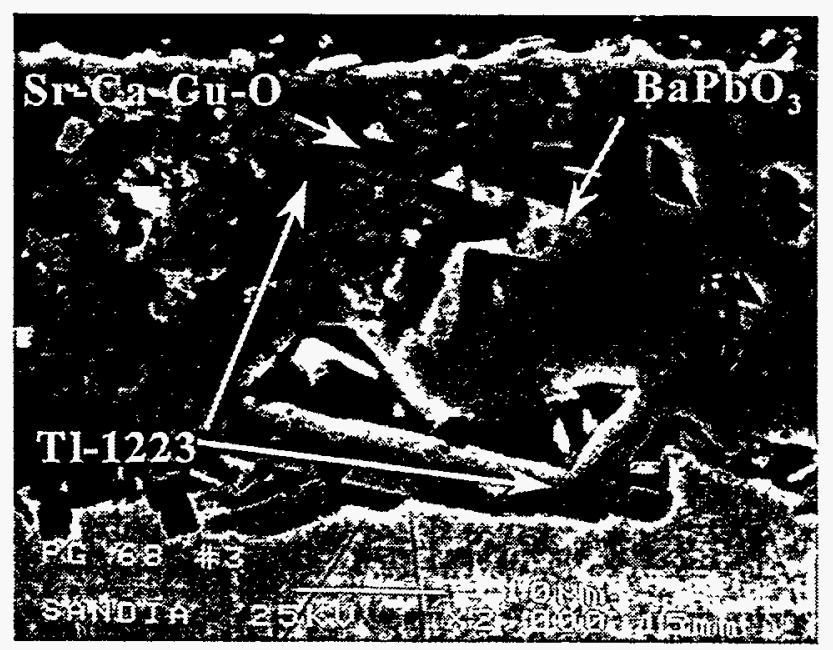

Figure 1-2. $\left(\mathrm{TI}_{0.5} \mathrm{~Pb}_{0.5}\right)\left(\mathrm{Sr}_{0.8} \mathrm{Ba}_{0.2}\right)_{2} \mathrm{Ca}_{2} \mathrm{Cu}_{3} \mathrm{O}_{\mathrm{x}}$

$+5 \mathrm{wt} \%$ Ag; 2000x.

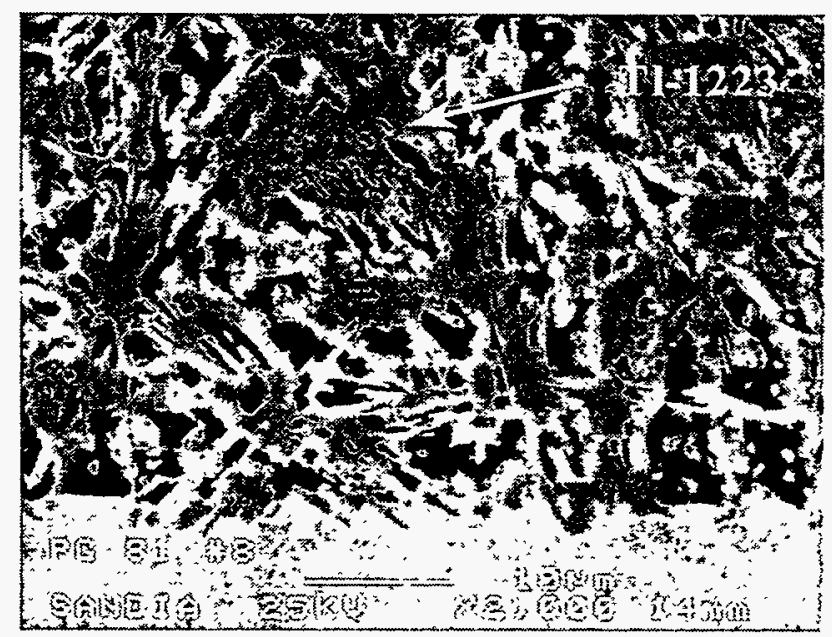

Figure 1-4. $\mathrm{Tl}_{1} \mathrm{Ba}_{2} \mathrm{Ca}_{2} \mathrm{Cu}_{3} \mathrm{O}_{\mathrm{x}}+5 \mathrm{wt} \% \mathrm{Ag}$; $2000 x$. 


\subsubsection{Transient Temperature Processing of $(\mathrm{Pb}, \mathrm{Sr})$-doped Tl-1223 Films in a Two-Zone}

\section{Furnace}

( $\mathrm{Pb}, \mathrm{Sr}$ )-doped $\mathrm{Tl}-1223$ dipcoated films were processed in our two-zone system to produce a large, blocky grain structure. We have tried to improve the intergranular links by producing transient melt events during the two-zone deposition process. Brief (10 $\mathrm{min}$ ) temperature excursions were produced during the early thallination phase as shown in Figure 1-5. Temperature excursions were typically in the range of $930^{\circ} \mathrm{C}$, then cooled to the longer-time processing temperature near $910^{\circ} \mathrm{C}$. This process raised the critical current from typical values of around 2.5 amps to a value of 5.5 amps. However, extended melting for periods exceeding 10 minutes was seen to reduce the critical current. This is an encouraging result indicating that short duration melting may by useful in linking the TI-1223 grains.

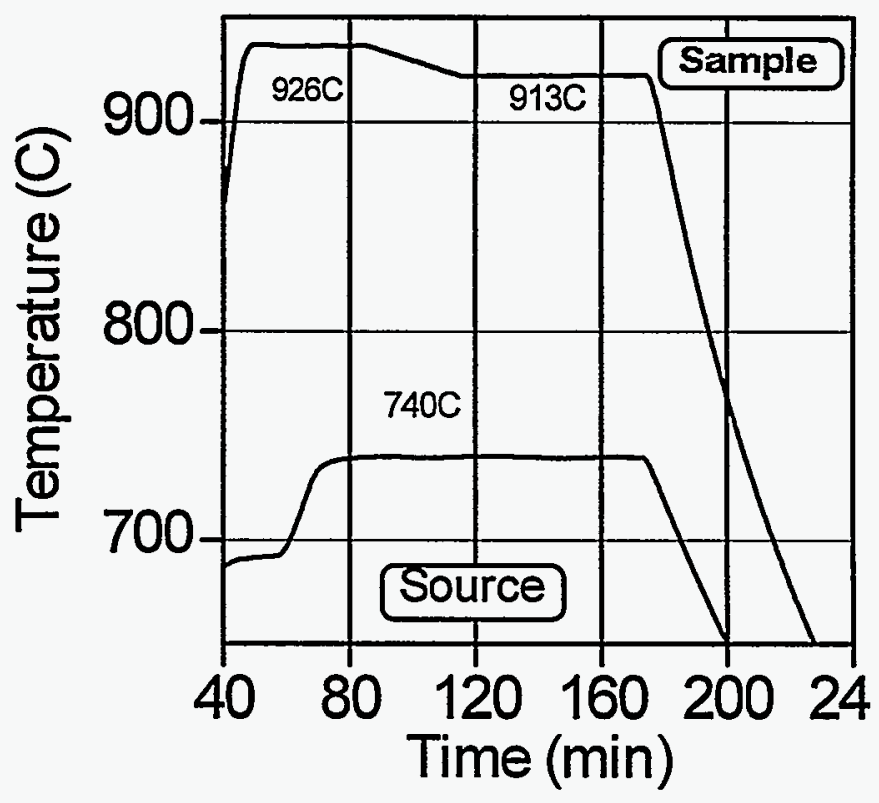

Figure 1-5. Temperature profile of transient-temperature two-zone run. 


\subsubsection{Transient Atmosphere Processing of ( $\mathrm{Pb}, \mathrm{Sr})$-doped Tl-1223 Films in a Two-Zone}

\section{Furnace}

Transient melting was induced in dipcoated films by varying the local atmosphere around the sample during thallination in the two-zone furnace. Reduced $\mathrm{pO}_{2}$ lowers the melt temperature of the superconductor coating while increasing the melt temperature of the silver substrate. This results in a wider processing window for the coated tapes.

However, lower $\mathrm{pO}_{2}$ causes a significant increase in the $\mathrm{Tl}_{2} \mathrm{O}$ overpressure above the $\mathrm{Tl}_{2} \mathrm{O}_{3}$ source. Therefore, a special ceramic tube insert was constructed which allowed a reduced $\mathrm{pO}_{2}$ (e.g. Ar, $\mathrm{N}_{2}$, air) gas flow around the sample while leaving the $\mathrm{pO}_{2}$ level around the $\mathrm{Tl}_{2} \mathrm{O}_{3}$ source unaffected. Figure 1-6 shows as a schematic of this system while Figure 1-7 shows the temperature profile during the run and the sequencing of the transient Ar pulse.

\section{Sample Source}

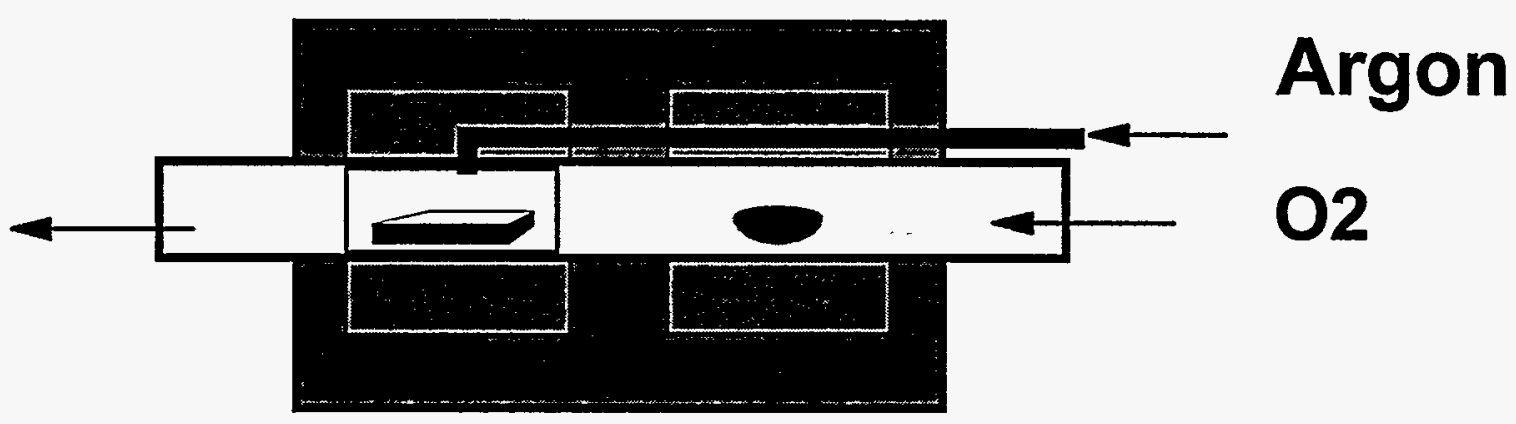

Figure 1-6. Schematic of transient-atmosphere two-zone furnace. 


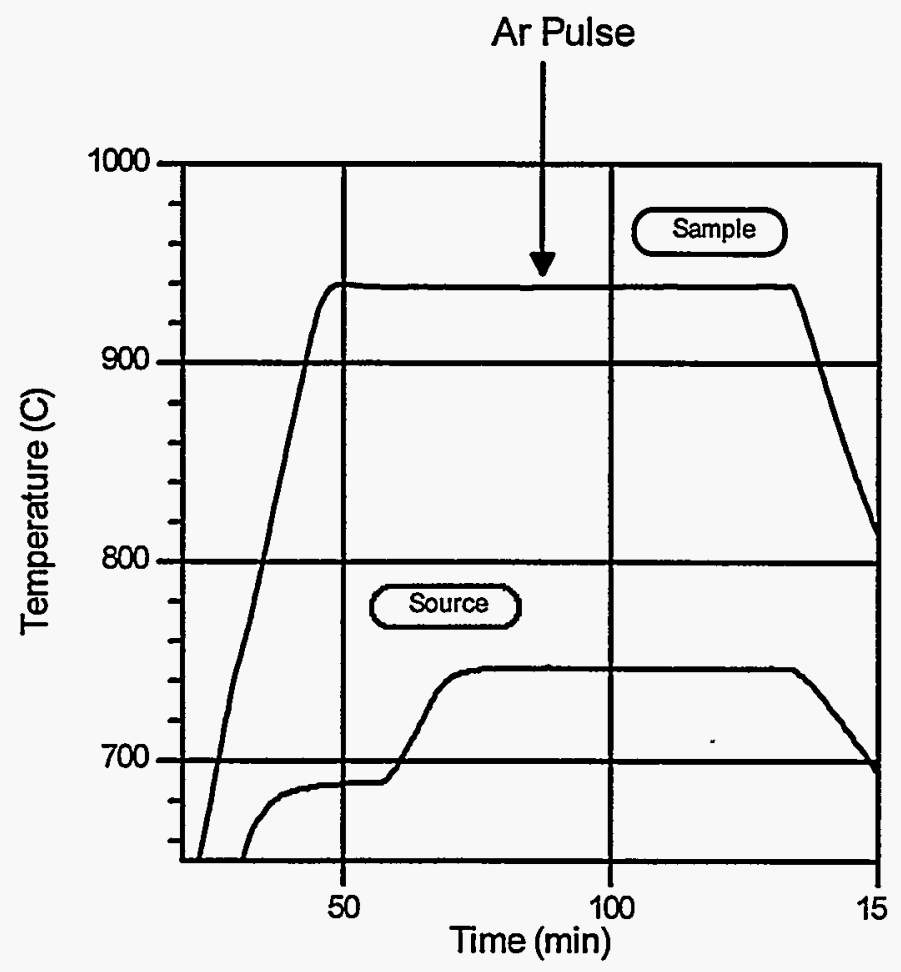

Figure 1-7. Temperature profile of transient-atmosphere run in two-zone furnace.

The optimum time period to induce the transient melting was investigated. Argon gas was introduced for a period of 5 minutes to produce the transient melt event. The Argon gas was introduced at time periods of $5,10,15,20$ and 30 minutes into the thallination phase. Figure 1-8 below shows the resulting critical currents measured for the samples. The sample temperature was maintained at $909^{\circ} \mathrm{C}$ while the $\mathrm{TI}$ source temperature was near $740^{\circ} \mathrm{C}$. We see that the low $\mathrm{pO}_{2}$ induced transient melt only produced increased critical current in a narrow time window around 10 minutes into the thallination step. Earlier or later melting had no effect. As better films are produced using advanced substrates, this technique may allow further enhanced performance. 


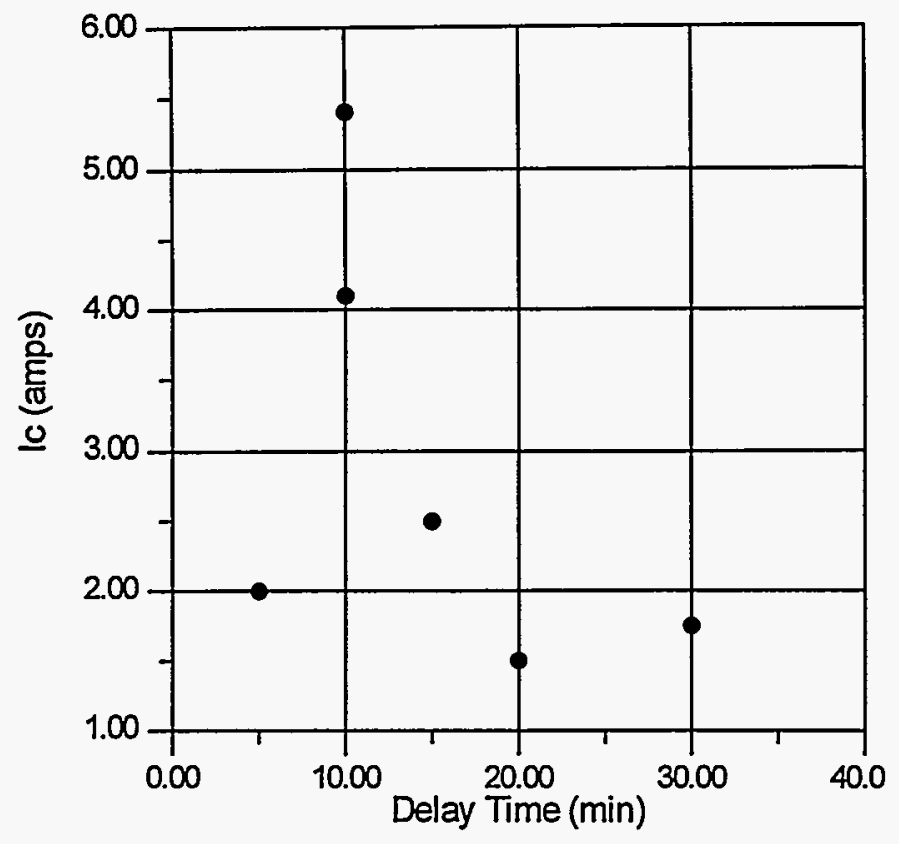

Figure 1-8. Critical currents for low $\mathrm{pO}_{2}$ induced transient melt processed films.

\subsection{Future Work}

The development of aligned crystal structures on metallic tapes is dependent on improvements in the metallic interface. Compatible material capable of maintaining a smooth interface at elevated temperatures is required coupled with deposition techniques which do not require mechanical processing steps which can distort the interface. The use of textured interfaces may also be required to develop strongly coupled grain structures. We plan to work on solgel based techniques to produce aligned buffer layers on nickel substrates produced by the RABiTs technique developed at ORNL. We will investigate possible advantages of TI-based coatings compared to the YBCO coatings currently being developed at ORNL and LANL. Single crystal substrates of crystallographic compatible materials will also be used to develop TI-based coatings in our two-zone furnace in preparation for the textured coatings. 


\section{Processing of Powder-in-Tube TI-1223 Tapes}

\subsection{Introduction}

Powder-in-Tube(PIT) processing has been pursued as a commercially scalable technique for producing long length conductors at economical rates. The combination of thermal and mechanical processing for PIT Bismuth tapes has successfully produced long tapes capable of operation at sub-liquid nitrogen temperatures. However, this standard technique has not been successful for the Thallium-based material. The Thallium compounds do not have the micaceous mechanical properties of the Bismuth material and thus do not easily form the aligned microstructure necessary for strong-link conduction. However, regions of long-length TI-1223 grains have been produced by processing in a temperature gradient. We investigated the microstructural development of Ag-clad tapes with different superconducting core compositions using a newly designed pull-through gradient furnace. The results of these experiments are described in the following sections.

\subsection{Progress in FY96}

\subsubsection{Pull-Through Temperature/Atmosphere Gradient Furnace Processing}

A furnace system was developed which allows tapes to be pulled through a temperature gradient in a chosen atmosphere and, if desired, into a different atmospheric region. Figure 2-1 shows a schematic of the system. This combination of temperature and atmosphere gradient processing is intended to induce enhanced textured grain growth in the tapes. Initial experiments with IGC have shown that grains of the (Pb,Sr)-doped Tl-1223 can be grown with lengths of over $100 \mu \mathrm{m}$. The tapes are pulled through a temperature gradient in the center ceramic tube under reduced $\mathrm{pO}_{2}$ (air or $\mathrm{Ar}$ ). This reduced $\mathrm{pO}_{2}$ results in a lower melting temperature for the superconductor and a higher melting temperature for the silver sheath, thus allowing a wider processing window. Pull rates as low as 0.5 inches/hr and as high as inches/min were used. The sample tape is attached to a ceramic holder which is monitored with a thermocouple to record the exact temperature/time profile during the run. The ceramic tube is positioned to allow the sample to exit the inner atmospheric 
region at a chosen temperature along the furnace temperature profile and undergo a transition into a region with higher $\mathrm{pO}_{2}$. This $\mathrm{pO}_{2}$ transition region can be adjusted by varying the relative flow rates of gases to the inner and outer tubes. The higher $\mathrm{pO}_{2}$ results in a more rapid recrystallization of the superconductor and allows the core to be reoxygenated.

Figure 2-2 shows a composite SEM image of a tape that had been pulled through the furnace at a rate of $1 \mathrm{inch} / \mathrm{hr}$ at a temperature of $910^{\circ} \mathrm{C}$ in an inner atmosphere of air and then into an outer oxygen atmosphere. The temperature gradient was 5 deg/inch. Long grains around $100 \mu \mathrm{m}$ in length were observed with preferential alignment along the length of the tape. Large regions of porosity were still present and are believed to form during the high-temperature melt period, resulting in the limited transport current. The results of our previous quench studies have shown that the regions of porosity are associated with higher $\mathrm{Sr}$ concentration. However, tapes with lower $\mathrm{Sr}$ content, $\left(\mathrm{Sr}_{1.2} \mathrm{Ba}_{0.8}\right)$, were prepared but still showed similar degrees of porosity development. Tapes with $\mathrm{Sr} / \mathrm{Ba}$ levels as low as $\mathrm{Sr}_{0.8} \mathrm{Ba}_{1.2}$ were produced and processed under similar conditions to the higher $\mathrm{Sr}$ content tapes. As can be seen in Figure 2-3, these tapes did show reduced porosity but did not exhibit the long grain texture development. The large regions of porosity development were observed to form at regions of "necking" in the tape where there is local stress concentration.

Processing was also investigated as a function of temperature, atmosphere, mechanical pressing, and reacted vs. unreacted cores. Table 2-1 summarizes typical results obtained for these various processing conditions. Comparison of the critical currents of the samples shows that no significant effect was seen due to variation of $\mathrm{Sr}$ level over the range $\mathrm{Sr}_{1.6}$ to $\mathrm{Sr}_{1.2}$. However, the tapes with $\mathrm{Sr}_{0.8}$ consistently showed the highest current levels. These higher currents were observed even though the critical temperature was about $10 \mathrm{~K}$ lower for the low $\mathrm{Sr}$ level samples. The tapes with higher Sr levels showed significant variation in critical current as a function of position along the tape while the $\mathrm{Sr}_{0.8}$ samples showed very consistent critical current values from the leading edge to the trailing edge. Processing temperatures of $900^{\circ} \mathrm{C}$ $925^{\circ} \mathrm{C}$ gave comparable results for all tapes. Higher processing temperatures in air resulted in significant pin hole development and partial melting of the sheath. The above data also showed that only slight improvement resulted from pre-annealing the 
tapes to form a reacted core. A light uniaxial press to compact the core after annealing also only resulted in a slight improvement in the current.

Although gradient processing has resulted in promising microstructures consisting of long, partially aligned grains, these tapes still have a high degree of porosity segregation which limits the transport current. Gradient processing combined with mechanical rolling and harder sheath materials may possibly offer improved performance.

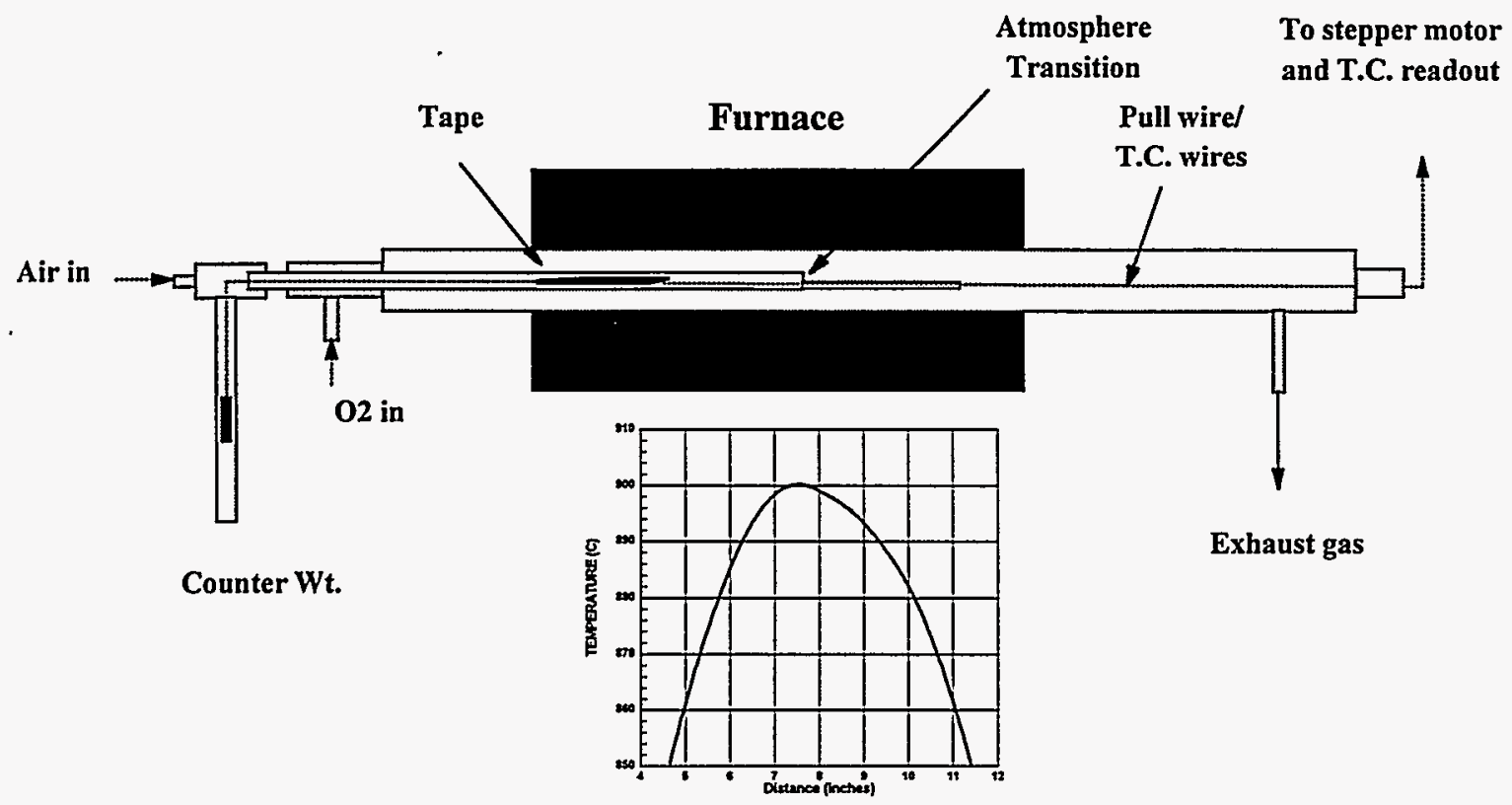

Figure 2-1. Pull-Through Temperature/Atmosphere Gradient Furnace. 


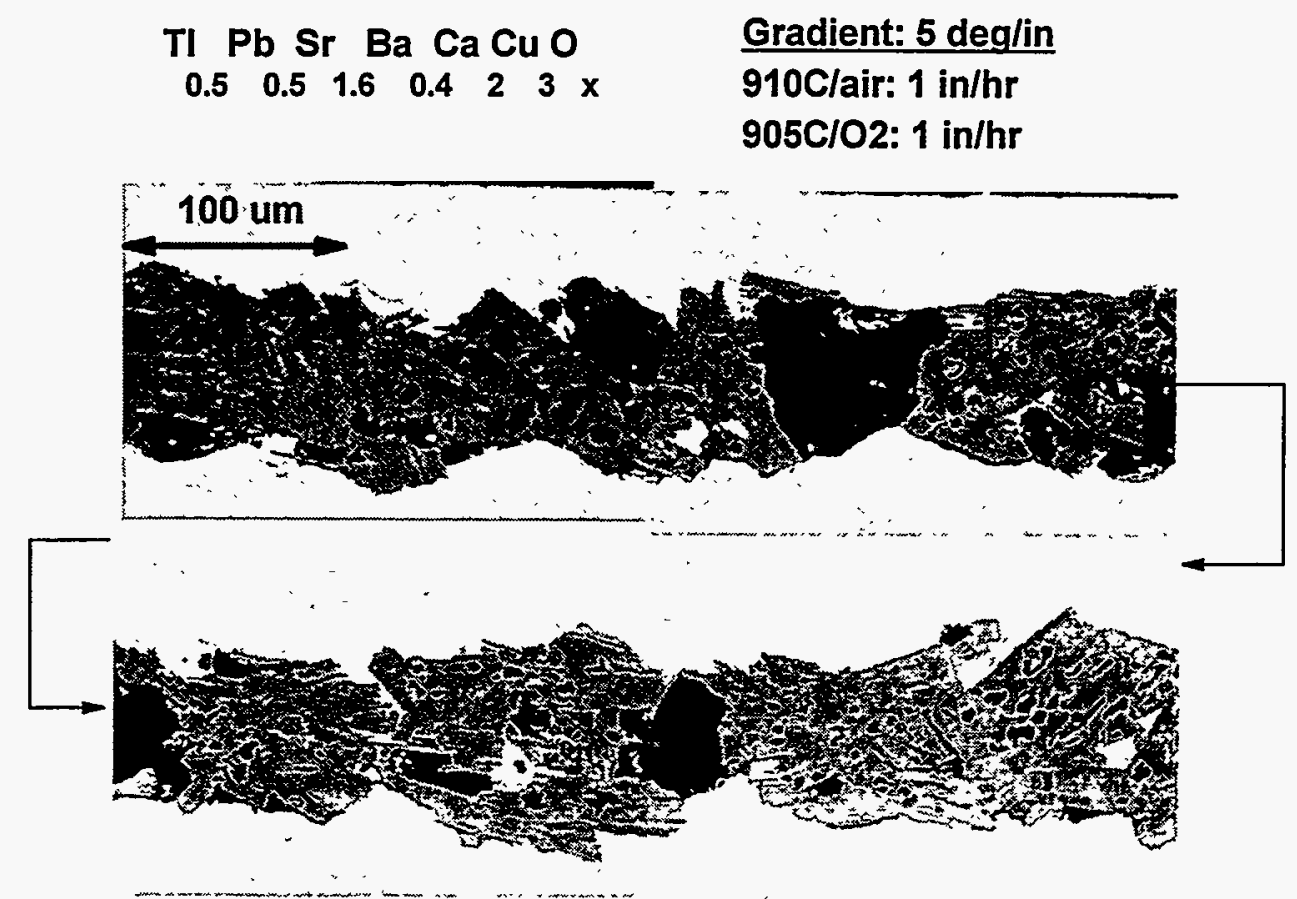

Figure 2-2. SEM collage of $\mathrm{Sr}_{1.6} \mathrm{Ba}_{0.4} \mathrm{TI}-1223$ block grain structure after pull-through processing.

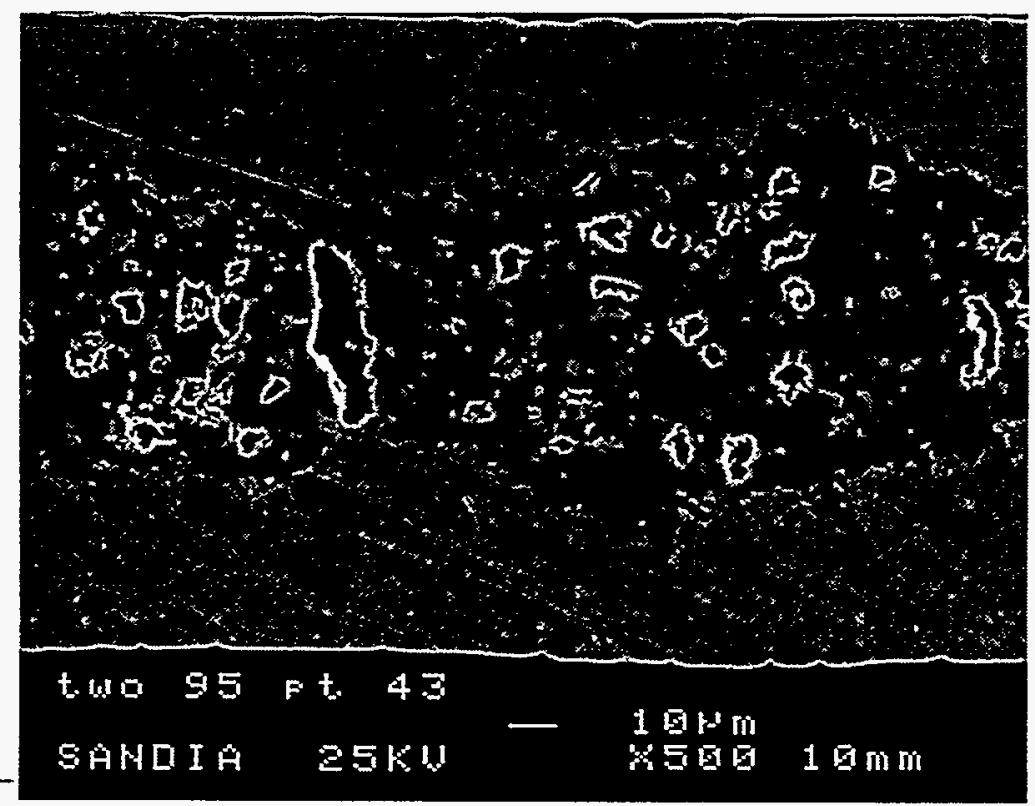

Figure 2-3. SEM micrograph of $\mathrm{Sr}_{0.8} \mathrm{Ba}_{1.2}$ composition tape processed in pull-through furnace. 
Table 2-1. Temperature/Atmosphere Gradient Furnace Processing

\begin{tabular}{|c|c|c|c|c|c|}
\hline $\mathrm{Sr}_{x} \mathrm{Ba}_{2-x}$ & ID & $\begin{array}{c}\text { Pre-anneal } \\
\text { Temp }\left({ }^{\circ} \mathrm{C}\right) / \text { time/atm } \\
\text { press }(\mathrm{kpsi})\end{array}$ & $\begin{array}{c}\text { Gradient } \\
\text { Temp }\left({ }^{\circ} \mathrm{C}\right) / \text { inner } \\
\text { atm /outer atm }\end{array}$ & $T_{c}(K)$ & $I_{c}(A)$ \\
\hline $\mathrm{Sr}_{1.6} \mathrm{Ba}_{0.4}$ & TW018A & none & 912/air/O & 101 & 1.2 \\
\hline $\mathrm{Sr}_{1.4} \mathrm{Ba}_{0.6}$ & TW090A & none & 914/air/O & 104 & 0.4 \\
\hline $\mathrm{Sr}_{1.4} \mathrm{Ba}_{0.6}$ & TW090B & none & 923/air/ $\mathrm{O}_{2}$ & 99 & 0.25 \\
\hline $\mathrm{Sr}_{1.2} \mathrm{Ba}_{0.8}$ & TW091A & none & 914/air/O $\mathrm{O}_{2}$ & 99 & 0.8 \\
\hline $\mathrm{Sr}_{1.2} \mathrm{Ba}_{0,8}$ & TW091B & none & 923/air/O ${ }_{2}$ & 106 & 1.8 \\
\hline $\mathrm{Sr}_{1,2} \mathrm{Ba}_{0,8}$ & TW091C & none & 923/air/air & 102 & 0.55 \\
\hline $\mathrm{Sr}_{1.2} \mathrm{Ba}_{0.8}$ & TW022A & none & 909/air/O ${ }_{2}$ & 108 & 1.3 \\
\hline $\mathrm{Sr}_{1.2} \mathrm{Ba}_{0.8}$ & TW022B & $\begin{array}{c}860 / 2 \mathrm{hr} / \mathrm{O}_{2} \\
\text { no press }\end{array}$ & 903/air/O $\mathrm{O}_{2}$ & 108 & 2.0 \\
\hline $\mathrm{Sr}_{1.2} \mathrm{Ba}_{0,8}$ & TW022C & $\begin{array}{l}860 / 2 \mathrm{hr} / \mathrm{O}_{2} \\
5 \mathrm{kpsi} \text { press }\end{array}$ & $897 /$ air/O $\mathrm{O}_{2}$ & 109 & 2.4 \\
\hline $\mathrm{Sr}_{1.2} \mathrm{Ba}_{0,8}$ & TW022D & $\begin{array}{l}880 / 2 \mathrm{hr} / \mathrm{O}_{2} \\
5 \mathrm{kpsi} \text { press }\end{array}$ & 910/air/O $\mathrm{O}_{2}$ & 108 & 1.6 \\
\hline $\mathrm{Sr}_{0.8} \mathrm{Ba}_{1.2}$ & TW095A & none & $905 /$ air $/ \mathrm{O}_{2}$ & 98 & 2. \\
\hline $\mathrm{Sr}_{0.8} \mathrm{Ba}_{1.2}$ & TW095B & none & 916/air/O ${ }_{2}$ & 98 & 2.5 \\
\hline
\end{tabular}




\subsection{Future Work}

The formation of aligned microstructures with no porosity segregation is highly dependent on the development of a sheath material which will give smooth interfaces at the superconductor core while still allowing ease of drawing and rolling. Further work in the area of gradient processing will await development of such improved sheath materials. 


\section{Process Research on the Synthesis of High-Temperature Superconductors}

\subsection{Introduction}

The development of high temperature superconducting wires with properties suitable for high-power electrical applications requires an extensive understanding of the thermal processing/microstructure relationships of the superconducting material. It is the goal of this project to develop such understanding for the TI-based class of high temperature superconductors. Specifically, we have focused on the $\mathrm{Pb}$ - and $\mathrm{Sr}$ substituted $\mathrm{Tl}_{1} \mathrm{Ba}_{2} \mathrm{Ca}_{2} \mathrm{Cu}_{3} \mathrm{O}_{\mathrm{x}}$ phase, $\mathrm{TI}-1223$, because of its high irreversibility line and the ease of formation of the desired Tl-1223 structure. In particular, we are interested in the phase development from the high-temperature melt region where we believe the growth of long, aligned grains of TI-1223 is possible. We have seen that these grain structures can be produced by thermal gradient processing near the melt temperature and IGC has shown that these grain structures have improved current transport in magnetic field.

In previous work, we have seen in the melt regime that silver rich regions alternating with $\mathrm{Sr}-\mathrm{Ca}-\mathrm{Cu}$ oxide regions form with a periodicity of about 100 micrometers. As the melt phase developed in time, the majority of the $\mathrm{Sr}-\mathrm{Ca}-\mathrm{Cu}$ oxide regions were consumed by the Ag-rich liquid leaving behind Sr-rich regions of concentrated porosity with the 100 micrometer periodicity. Thus, the origin of the current-limiting porous regions appears to be related to the segregation of $\mathrm{Sr}-\mathrm{Ca}-\mathrm{Cu}$ oxide phases and the fact the strontium may not be incorporated into the Ag-rich liquid region. In an attempt to minimize this effect, compositions with reduced strontium were prepared by our coprecipitation process, fabricated into wires, and melt processed. Quench studies were performed in collaboration with IGC and LANL on wire samples with these compositions to determine the fundamental effect altering the strontium content has on the melt-regrowth process.

\subsection{Progress in FY96}




\subsubsection{Quench Studies of Microstructural Development in Tl-1223 Tapes with Varying}

Sr/Ba Ratios

In an attempt to minimize this porosity segregation, tapes with lower $\mathrm{Sr} / \mathrm{Ba}$ ratios were prepared: $\left(\mathrm{Tl}_{0.5} \mathrm{~Pb}_{0.5}\right)\left(\mathrm{Sr}_{0.7} \mathrm{Ba}_{0.3}\right)_{2} \mathrm{Ca}_{2} \mathrm{Cu}_{3} \mathrm{O}_{\mathrm{x}}$ and $\left(\mathrm{TI}_{0.5} \mathrm{~Pb}_{0.5}\right)\left(\mathrm{Sr}_{0.6} \mathrm{Ba}_{0.4}\right)_{2} \mathrm{Ca}_{2} \mathrm{Cu}_{3} \mathrm{O}_{\mathrm{x}}$. In addition, a $\mathrm{Sr}_{1.4} \mathrm{Ba}_{0.6}$ compound was prepared with $\mathrm{TIF}$ added as a partial substitution for the $\mathrm{Tl}_{2} \mathrm{O}_{3}$. TIF is believed to act as a fluxing agent and improve grain boundary interconnection. The Sandia chemprep powders were prepared and vacuum calcined at LANL and processed into tapes at IGC. The tapes were initially taken into their melt regime $\left(910^{\circ} \mathrm{C}-920^{\circ} \mathrm{C}\right)$ in air for 15 minutes and then quenched. Figure 3-1 shows a representation of the thermal schedule and Figure 3-2 shows a collage of SEM micrographs of one of the tapes. At $910^{\circ} \mathrm{C}$, porosity is concentrated in regions of "necking" where higher stress levels are to be expected. The microstructure consists of grains of TI-1212 surrounded by a Ag-rich liquid phase containing many of the other metallic species $(\mathrm{Tl}, \mathrm{Pb}, \mathrm{Cu})$. At $920^{\circ} \mathrm{C}$, large regions of porosity have begun to segregate. These porous regions have been seen to persist even after extensive thermal gradient processing of the tape. These initial results indicate that processing at lower temperatures may be an important parameter in limiting this porous microstructure development.

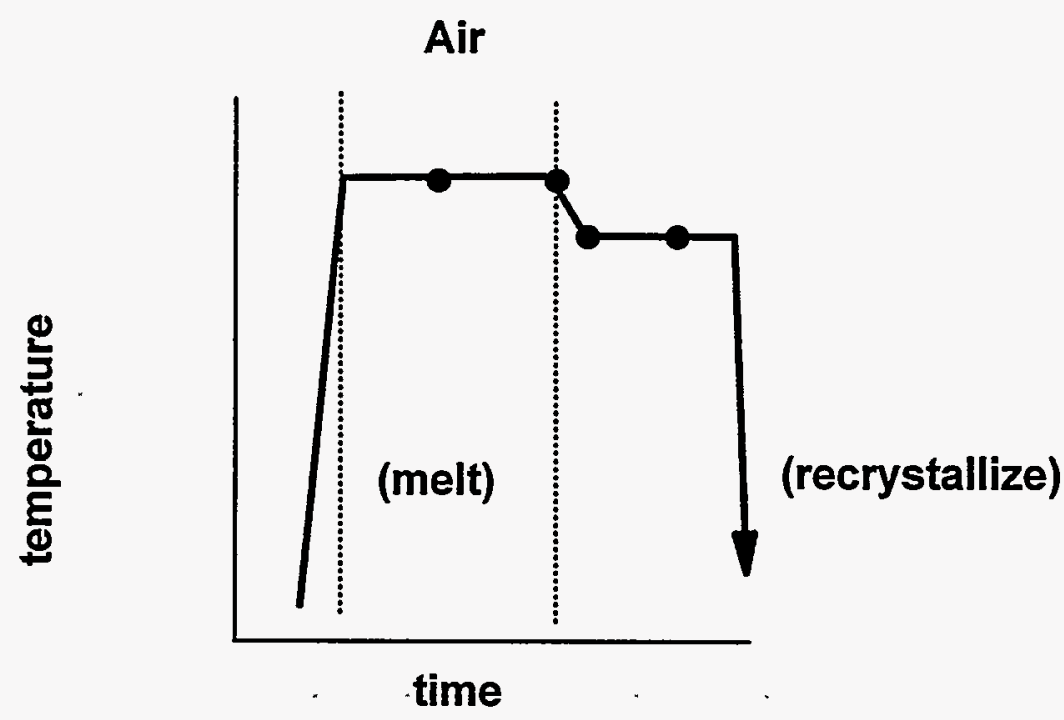

Figure 3-1. Thermal schedule for quench experiments. 


\section{Tl-1223}

\section{Breakdown}

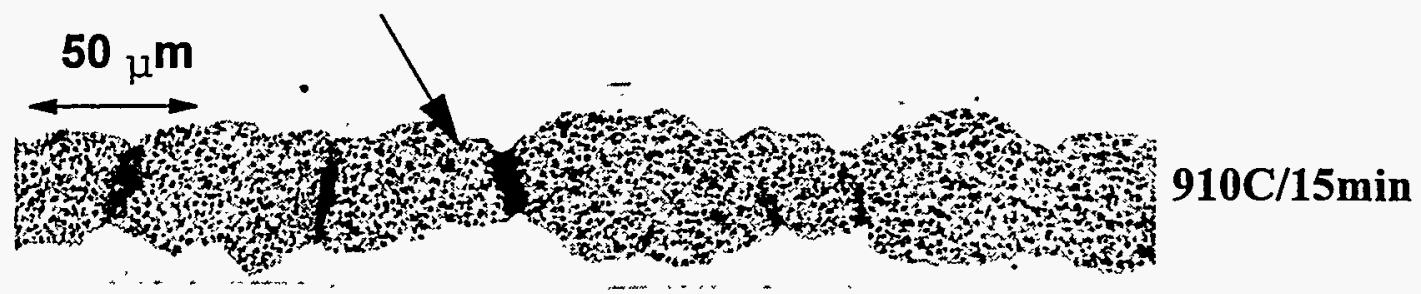

Porosity

Segregation

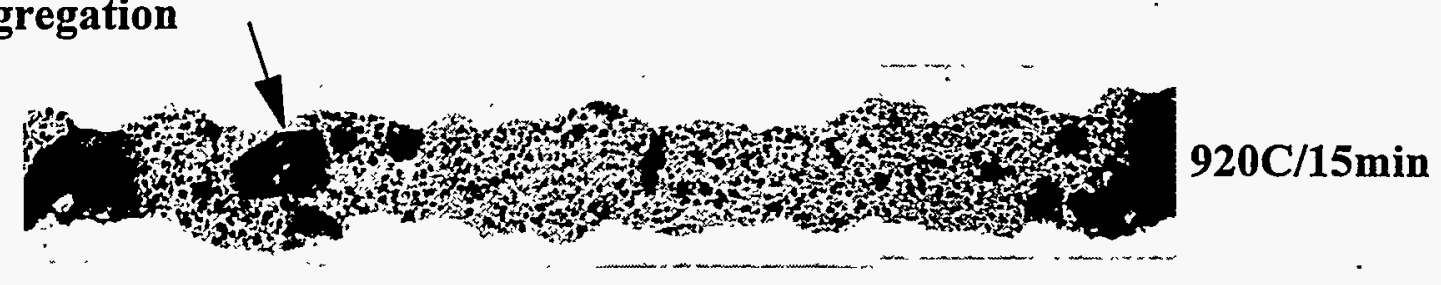

Figure 3-2. SEM micrographs showing collage pictures of quenched tape microstructures.

The breakdown of the TI-1223 at high temperatures and the subsequent recrystallization on cooling follows the path indicated in Figure 3-3. The TI-1223 grains undergo heterogeneous melting in the $910^{\circ} \mathrm{C}-930^{\circ} \mathrm{C}$ range in air, decomposing to $\mathrm{Tl}-1212$, Sr-Ca-Cu oxides and a Ag-containing melt. Figure 3-4 shows this progressive transformation at temperatures of $910^{\circ} \mathrm{C}, 920^{\circ} \mathrm{C}$ and $930^{\circ} \mathrm{C}$. Extensive porosity is indicated by the dark regions. TEM analysis of the intergranular regions was performed at ANL and showed Tl-1212 grains growing from a Ag-containing amorphous region rich in $\mathrm{Tl}, \mathrm{Pb}$ and $\mathrm{Cu}$. Also seen were islands of $\mathrm{CaO}$ containing measurable amounts of $\mathrm{TI}, \mathrm{Sr}, \mathrm{Cu}$ and $\mathrm{Ag}$.

No significant difference was seen between the three compositions in the melt regime $910^{\circ} \mathrm{C}-930^{\circ} \mathrm{C}$. However, the TIF containing composition showed enhanced growth kinetics when cooled rapidly from the melt regime to $880^{\circ} \mathrm{C}$. Figures $3-5$ and 3-6 compare the microstructures seen for a 5 minute hold at $880^{\circ} \mathrm{C}$ for the $\mathrm{Tl}_{2} \mathrm{O}_{3}$ and the $\mathrm{TIF} / \mathrm{Tl}_{2} \mathrm{O}_{3}$ compositions, respectively. Figure 3-5 shows more of the Ag-rich melt phase intermixed with the developing Tl-1212 grains while Figure 3-6 shows that the TIF containing compound had a more developed TI-1212 grain structure. This enhanced grain growth is shown developing in time in Figure 3-7. After 90 minutes at $880^{\circ} \mathrm{C}$, large blocky grains of $\mathrm{TI}-1223$ are seen with discrete regions of porosity. 
Fine Grained $(\mathrm{Pb}, \mathrm{Sr}) \mathrm{TI}-1223$

$\left(\sim 910^{\circ} \mathrm{C}-930^{\circ} \mathrm{C}\right.$ air)

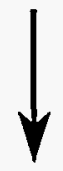

Ag-containing melt + Sr-Ca-Cu oxides + Tl-1212

(cooling)

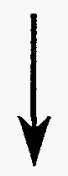

Form large grains of $\mathrm{Tl}-1212$

(cooling)

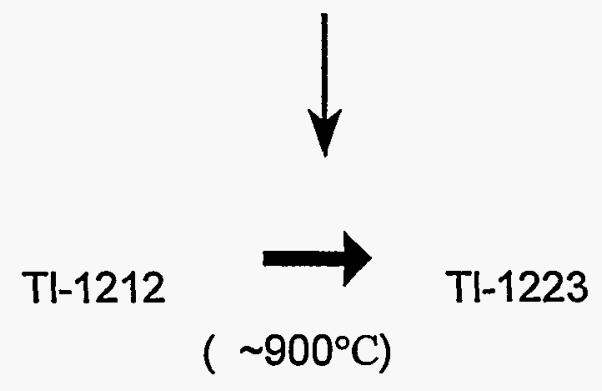

Figure 3-3. Microstructural development of $\mathrm{Tl}-1223 / \mathrm{Tl}-1212$ from the melt regime. 

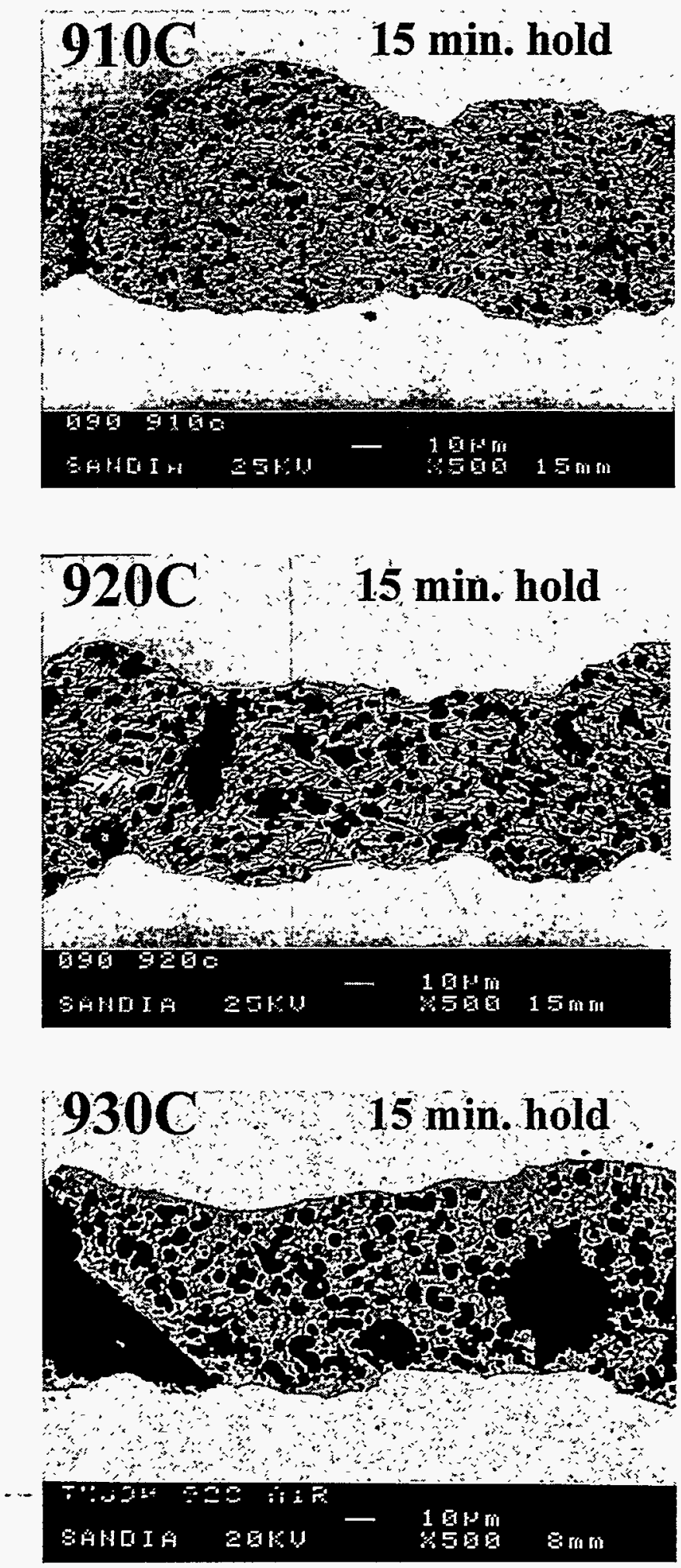

Figure 3-4. Melt decomposition of the TI-1223 microstructure. 


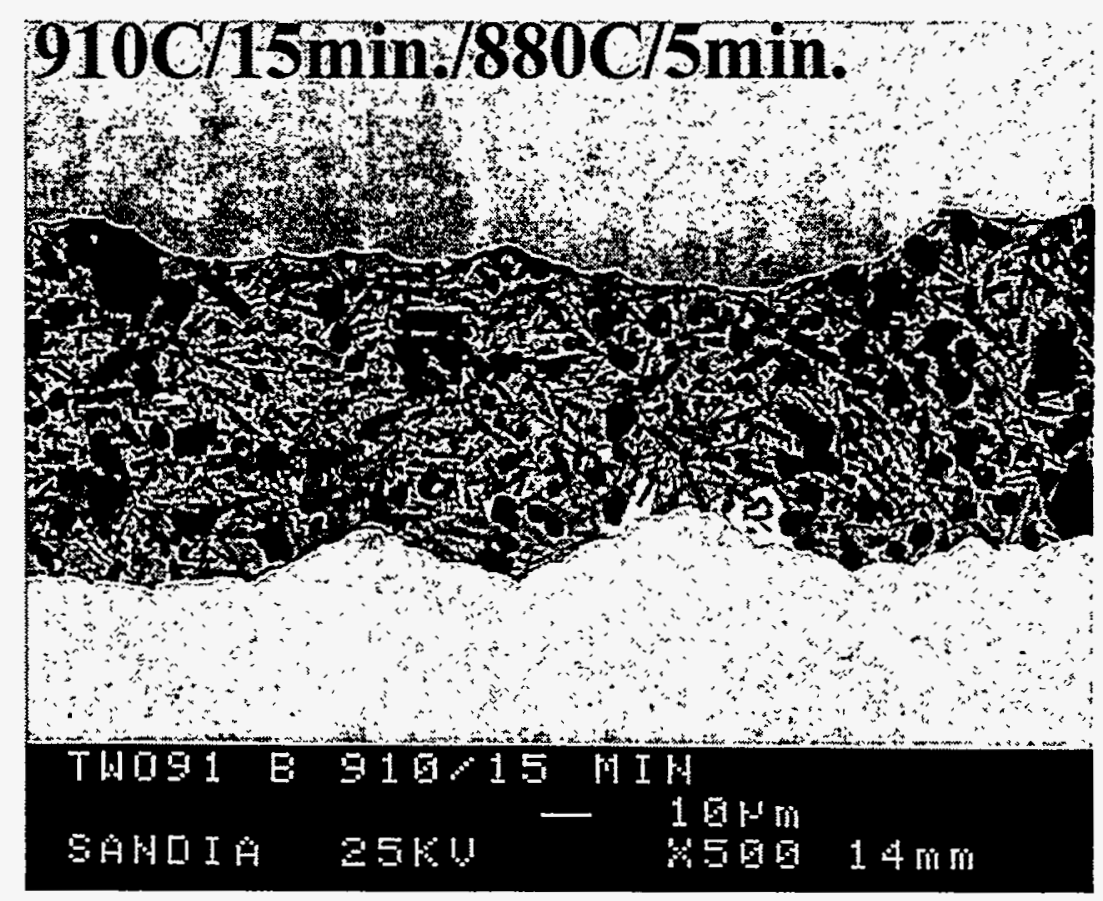

Figure 3-5. Developing microstructure of $\mathrm{Tl}_{2} \mathrm{O}_{3}$ based core at $880^{\circ} \mathrm{C}$.

\section{C/15min./880C/5min.}
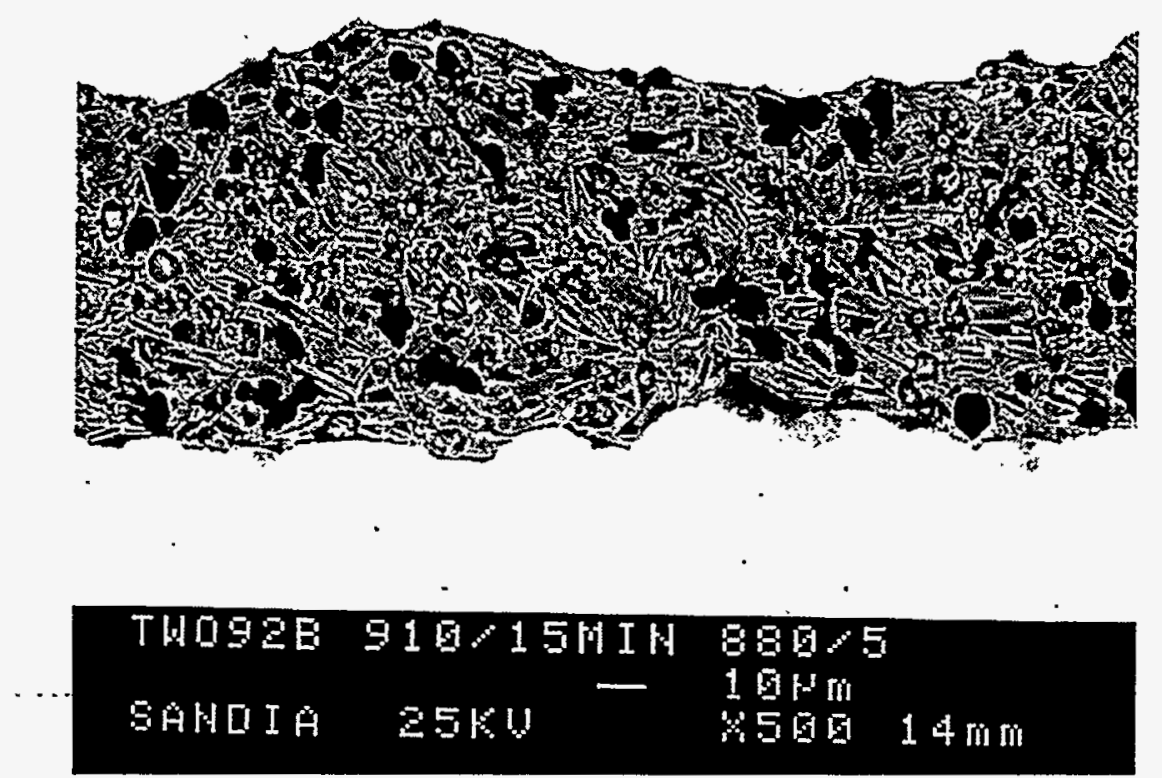

Figure 3-6. Developing microstructure of $\mathrm{Tl}_{2} \mathrm{O}_{3} / \mathrm{TIF}$ based core at $880^{\circ} \mathrm{C}$. 


\section{C/15min.}

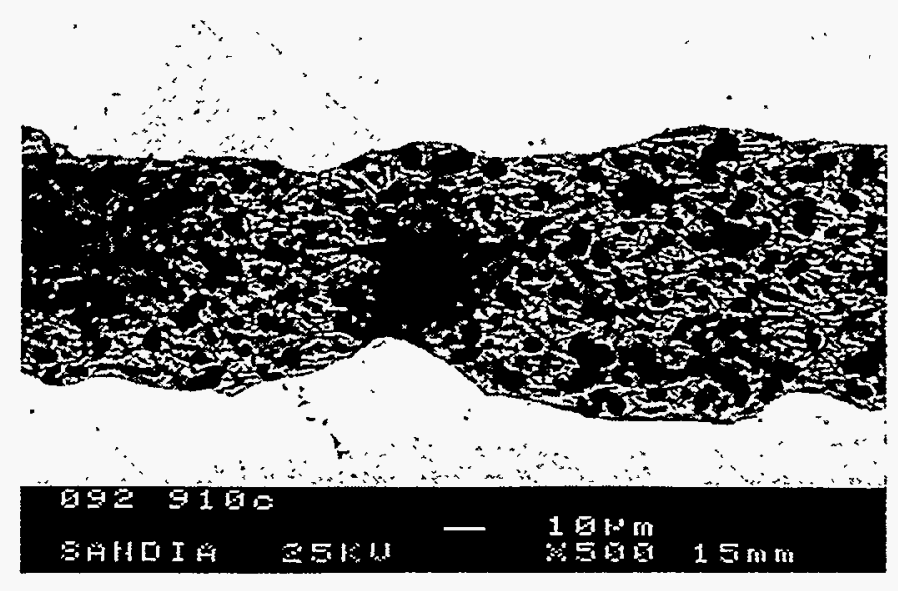

\section{C/15min./880C/5min.}

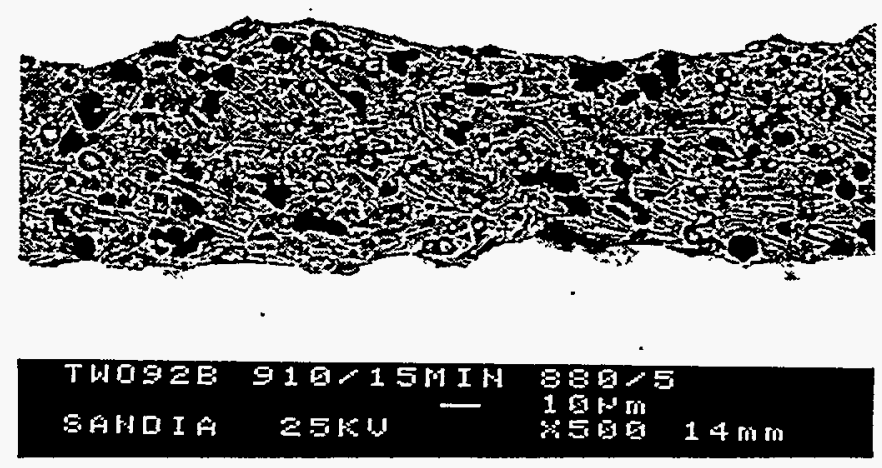

\section{C/15min./880C/90min.}

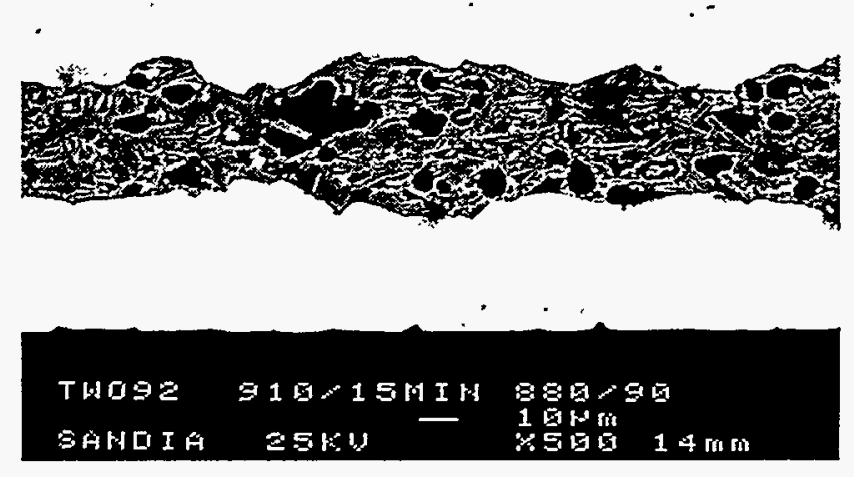

Figure 3-7. Time development of $\mathrm{Tl}_{2} \mathrm{O}_{3} / \mathrm{TIF}$ containing core at $880^{\circ} \mathrm{C}$. 


\subsection{Future Work}

Quench studies have shown that the melt/regrowth process for the $\left(\mathrm{Tl}_{0.5} \mathrm{~Pb}_{0.5}\right)\left(\mathrm{Sr}_{0.8} \mathrm{Ba}_{0.2}\right)_{2} \mathrm{Ca}_{2} \mathrm{Cu}_{3} \mathrm{O}_{\mathrm{x}}$ system is very complex. Variations in stoichiometry have not resulted in an easy solution to the problem of void segregation and texture development. Variations in wire cross section and lack of interface smoothness have limited homogeneous microstructural development. Further processing studies will necessarily have to wait on improvements in sheath material and thermal/mechanical processing techniques. 


\section{Effects of Fluxing Agents on Microstructural Development of TI-1223}

\subsection{Introduction}

Reports by Tachikawa suggest that TIF may result in improved strong links and higher irreversibility lines in the TI-1223 system. His study was limited to diffusion couples in the $\mathrm{Tl}_{1} \mathrm{Ba}_{2} \mathrm{Ca}_{2} \mathrm{Cu}_{3} \mathrm{O}_{\mathrm{x}}$ system and showed $\mathrm{Jc} \sim 2 \times 10^{4} \mathrm{~A}_{\mathrm{cm}}$. We choose to look at the effects of TIF substitution for $\mathrm{Tl}_{2} \mathrm{O}_{3}$ in both the $\mathrm{Pb}-\mathrm{Sr}$-doped $\mathrm{TI}-1223$ and the undoped $\mathrm{TI}-1223$ system. We also investigate the effects of $\mathrm{Ag}$ addition to the precursor powders.

\subsection{Progress in FY96}

\subsubsection{TIF substitute for $\mathrm{Tl}_{2} \mathrm{O}_{3}$ in $\left(\mathrm{TI}_{0.5} \mathrm{~Pb}_{0.5}\right)\left(\mathrm{Sr}_{0.8} \mathrm{Ba}_{0.2}\right)_{2} \mathrm{Ca}_{2} \mathrm{Cu}_{3} \mathrm{O}_{x}$ and $\mathrm{Tl}_{1} \mathrm{Ba}_{2} \mathrm{Ca}_{2} \mathrm{Cu}_{3} \mathrm{O}_{x}$} compositions.

We chose to investigate the effects of TIF in starting powder compositions of $\mathrm{Pb}_{0.5}\left(\mathrm{Sr}_{0.8} \mathrm{Ba}_{0.2}\right)_{2} \mathrm{Ca}_{2} \mathrm{Cu}_{3} \mathrm{O}_{\mathrm{x}}+5 \mathrm{wt} \% \mathrm{Ag}(\mathrm{CBC}-6), \mathrm{Pb}_{0.5}\left(\mathrm{Sr}_{0.8} \mathrm{Ba}_{0.2}\right)_{2} \mathrm{Ca}_{2} \mathrm{Cu}_{3} \mathrm{O}_{\mathrm{x}}(\mathrm{CBC}-10)$, and $\mathrm{Ba}_{2} \mathrm{Ca}_{2} \mathrm{Cu}_{3} \mathrm{O}_{x}+5 w t \% \mathrm{Ag}(\mathrm{CBC}-14)$. Initially, precursor powders of the selected stoichiometries were prepared and pressed into pellets. The pellets were sealed in $\mathrm{Au}$ foil in an oxygen atmosphere and then thermally processed to determine microstructural development. Processing was performed at temperatures of $830^{\circ} \mathrm{C}$, $860^{\circ} \mathrm{C}$ and $900^{\circ} \mathrm{C}$. Magnetization was used as the primary characterization tool and the results are summarized in Table 4-1. Phases are identified by transition temperature and $\%$ conversion was determined by shielding slope at $5 \mathrm{~K}$. The Meissner curves of the three compositions are shown in Figures 4-1, 4-2 and 4-3 for each temperature.

The undoped pellet (CBC-14), $\mathrm{Tl}_{1} \mathrm{Ba}_{2} \mathrm{Ca}_{2} \mathrm{Cu}_{3} \mathrm{O}_{x}+5 w t \% \mathrm{Ag}$, showed only $\mathrm{Tl}-1223$ phase development but, under these $\mathrm{O}_{2}$ atmospheric conditions, did not show substantial reaction until $900^{\circ} \mathrm{C}$ (Figure 4-1). The $\mathrm{Pb}$-, Sr-doped compositions behaved very differently depending on the presence of $\mathrm{Ag}$. The non-Ag containing material (CBC-10) shown in Figure 4-2 did not show any phase development up to $900^{\circ} \mathrm{C}$ except for trace $\mathrm{TI}-1212$, while the $\mathrm{Ag}$ containing material (CBC-6) shown in 
Figure 4-3 showed a steady increase in the superconductor phases. The CBC-6 material started with a $\mathrm{TI}-1212(22 \%)$ composition at the lower temperature and proceeded through a mixed phase region of TI-1212/TI-1223 (32\%) and then reached full TI-1223 (84\%) conversion. at the upper temperature $\left(900^{\circ} \mathrm{C}\right)$. SEM analysis of the $860^{\circ} \mathrm{C}$ processed samples showed a highly mixed-phase microstructure as shown in Figures 4-4 (CBC-6) and 4-5 (CBC-14) for the undoped and doped samples. The undoped sample with no $\mathrm{Ag}(\mathrm{CBC}-10)$ was mostly unreacted oxides. For these mixed precursor/TIF powders, Ag seems to play an important role in microstructural development, possibly through enhanced melting.

Table 4-1. Phases and $\%$ conversion

\begin{tabular}{|c|c|c|c||}
\hline \multicolumn{4}{|c|}{ TIF prepared pellets sealed in Au pouch under $\mathrm{O}_{2}$} \\
\hline \hline & $830^{\circ} \mathrm{C}$ & $860^{\circ} \mathrm{C}$ & $900^{\circ} \mathrm{C}$ \\
\hline CBC-6 & 1212 & $\underline{1212 / 1223}$ & 1223 \\
$(\mathrm{~Pb}-, \mathrm{Sr}-$ doped $+\mathrm{Ag})$ & $\sim 22 \%$ & $\sim 32 \%$ & $\sim 84 \%$ \\
\hline CBC-10 & 1212 & 1212 & 1212 \\
$(\mathrm{~Pb}-, \mathrm{Sr}-$ doped, no Ag) & $<5 \%$ & $<5 \%$ & $\sim 5 \%$ \\
& & & \\
\hline CBC-14 & 1223 & 1223 & 1223 \\
(undoped + Ag) & $\sim 6 \%$ & $\sim 10 \%$ & $\sim 45 \%$ \\
\hline
\end{tabular}

(dominant phase underlined) 


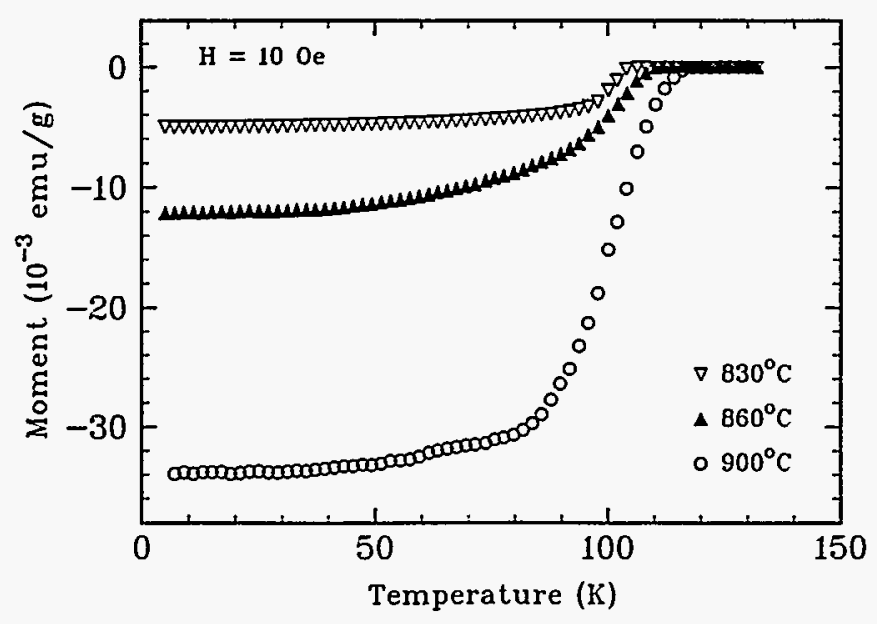

Figure 4-1. $\mathrm{Tl}_{1} \mathrm{Ba}_{2} \mathrm{Ca}_{2} \mathrm{Cu}_{3} \mathrm{O}_{\mathrm{x}}+5 w t \%$ Ag: sealed Au pouch.

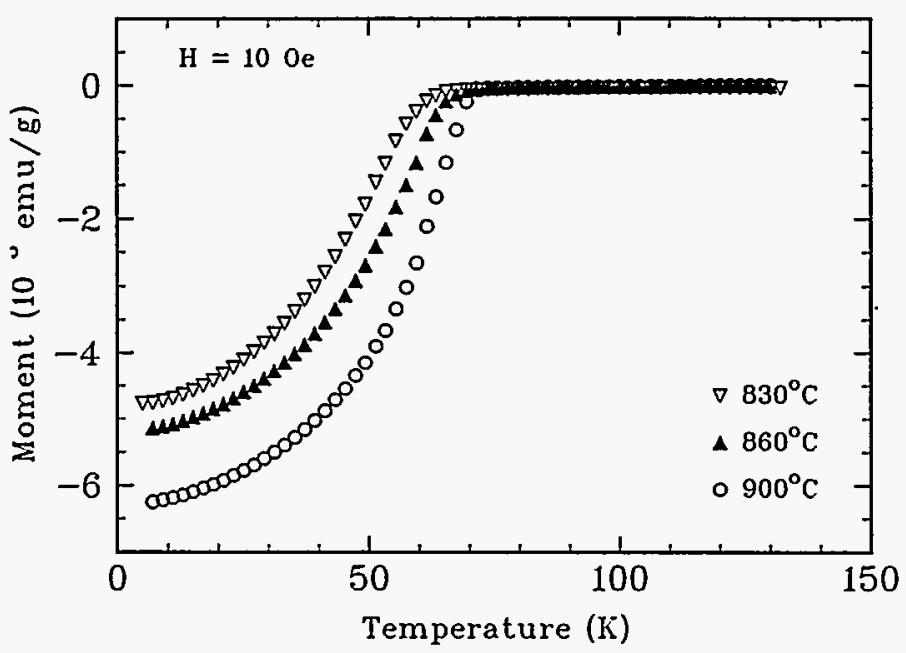

Figure 4-2. $\left(\mathrm{TI}_{0.5} \mathrm{~Pb}_{0.5}\right)\left(\mathrm{Sr}_{0.8} \mathrm{Ba}_{0.2}\right)_{2} \mathrm{Ca}_{2} \mathrm{Cu}_{3} \mathrm{O}_{\mathrm{x}}$ : sealed Au pouch.

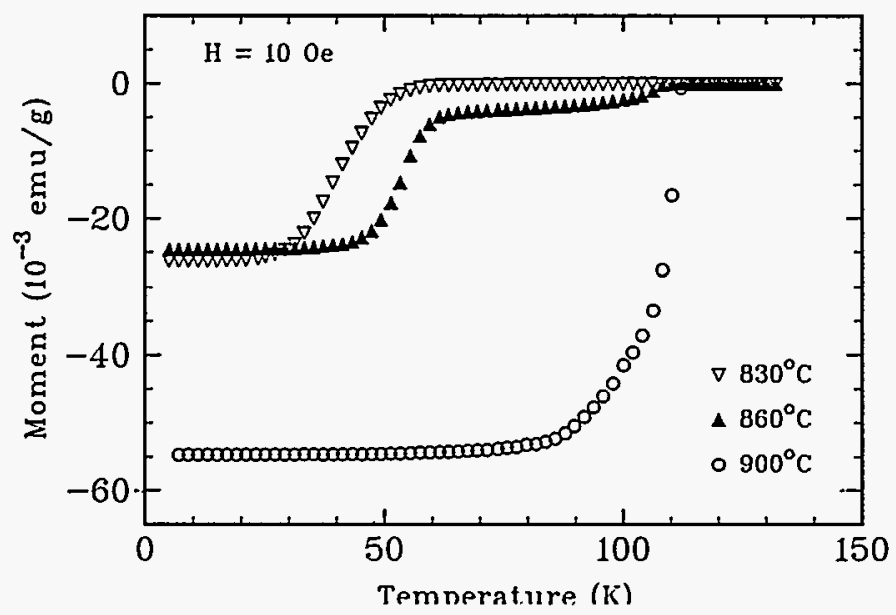

Figure 4-3. $\left(\mathrm{Tl}_{0.5} \mathrm{~Pb}_{0.5}\right)\left(\mathrm{Sr}_{0.8} \mathrm{Ba}_{0.2}\right)_{2} \mathrm{Ca}_{2} \mathrm{Cu}_{3} \mathrm{O}_{\mathrm{x}}+5 w t \%$ Ag: sealed Au pouch. 


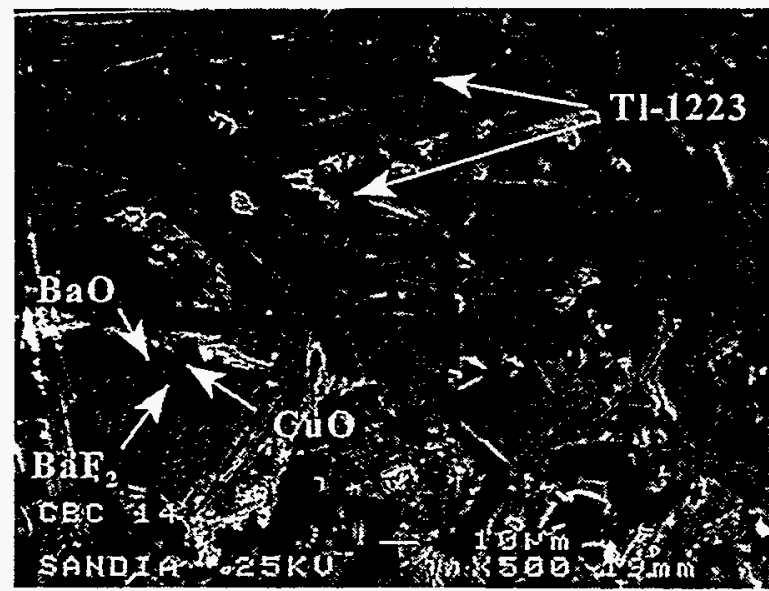

Figure 4-4. $\mathrm{CBC}-14$ (undoped $+\mathrm{Ag}$ )

TIF/precursor pellet; $860^{\circ} \mathrm{C} / \mathrm{O}_{2} / \mathrm{Au}$ pouch; 500x.

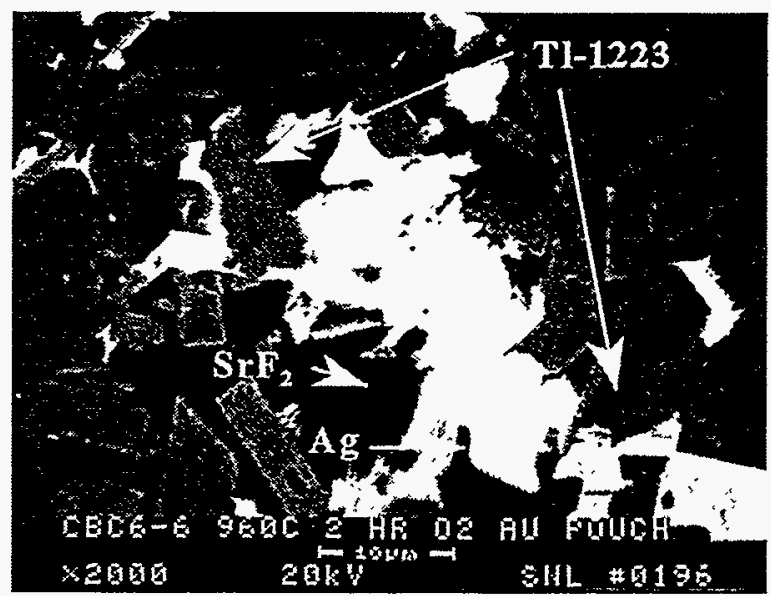

Figure 4-5. $\mathrm{CBC}-6$ (Pb-,Sr-doped $+\mathrm{Ag})$ TIF/precursor pellet; $860^{\circ} \mathrm{C} / \mathrm{O}_{2} / \mathrm{Au}$ pouch; 2000x.

Pellets of the precursor powders were also prepared, sintered, and then coated with a 100 $\mu \mathrm{m}$ layer of TIF. These pellets were placed, unsealed, in a tube furnace and baked at $860^{\circ} \mathrm{C}$ for one hour in flowing $\mathrm{O}_{2}$. Table 4-2 summarizes the phase development as indicated by magnetization measurements. Figures 4-6 and 4-7 show the Meissner curves for the non-Ag containing samples and $\mathrm{Ag}$ containing samples respectively. The low-temperature upturn in the magnetization indicates paramagnetic behavior of unreacted/secondary phases. In contrast to the sealed pellets, silver had a detrimental effect, resulting primarily in conversion to the TI1212 phase. Likewise, the doped precursor material did not perform as well, resulting in Tl-1212 or low-level TI-1223. The non-Ag containing, undoped sample (CBC-17) showed the greatest degree of conversion to Tl-1223. 
Table 4-2. Phases and \% conversion

\begin{tabular}{|c|c|}
\hline \multicolumn{2}{|c|}{$\begin{array}{c}\text { TIF coated pellets } 860^{\circ} \mathrm{C} / \text { open } \\
\text { furnace } / \mathrm{O}_{2}\end{array}$} \\
\hline $\begin{array}{c}\text { CBC-6 } \\
(\mathrm{Pb}-, \mathrm{Sr}-\mathrm{doped}+\mathrm{Ag})\end{array}$ & $\frac{1212 / 1223}{\sim 20 \%}$ \\
\hline $\begin{array}{c}\mathrm{CBC}-10 \\
\text { (Pb-,Sr-doped, no } \\
\mathrm{Ag})\end{array}$ & $\begin{array}{r}1223 \\
\sim 30 \%\end{array}$ \\
\hline $\begin{array}{c}\text { CBC-14 } \\
\text { (undoped }+\mathrm{Ag} \text { ) }\end{array}$ & $\begin{array}{r}1212 \\
\sim 20 \%\end{array}$ \\
\hline $\begin{array}{c}\mathrm{CBC}-17 \\
\text { (undoped, no Ag) }\end{array}$ & $\begin{array}{l}1223 \\
\sim 40 \%\end{array}$ \\
\hline
\end{tabular}
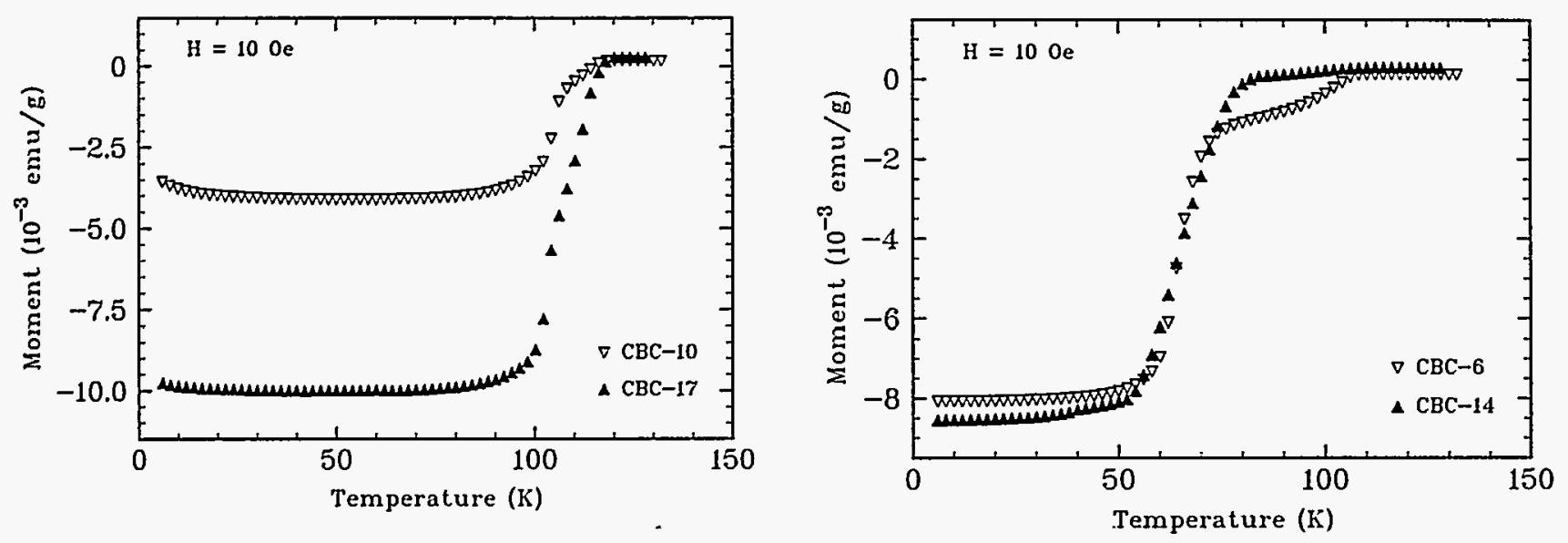

Figure 4-6. Non-Ag containing precursor. Figure 4-7. $5 w t \% \mathrm{Ag}$ containing precursor. CBC-10; Pb-,Sr-doped; CBC-17 undoped CBC-6; Pb-,Sr-doped; CBC-14; undoped TIF coated pellets, $860^{\circ} \mathrm{C}$, open furnace. TIF coated pellets, $860^{\circ} \mathrm{C}$, open furnace. 


\subsection{Future Work}

The role of TIF is obviously a complex one in this system. The substitution of TIF for $\mathrm{Tl}_{2} \mathrm{O}_{3}$ does not result in any marked improvement in microstructural development. However, small additions of TIF have been seen to give some improvement in long grain growth as seen in the gradient furnace processed tapes and in the quenched tapes. Further study will be limited to studies of near optimized tapes and films. 


\section{Cryogenic Design of a High-Temperature Superconducting (HTS) Motor}

\subsection{Introduction}

A HTS motor allows increased electrical efficiency and reduced size and weight electrical devices. This translates to a potentially significant savings for US industry. Sandia has aided Reliance Electric and American Superconductor in the development of a 10,000 hp superconducting motor as part of the Superconductivity Partnership Initiative (SPI). This has been done by building a series of motors of increased size. This year the program has demonstrated the $125 \mathrm{hp}$ design which has achieved over $200 \mathrm{hp}$. Sandia National Laboratories' efforts in this fiscal year were concentrated in the heat transport aspects of the motor. SNL's goals were to: 1.) collaborate-with the SPI team on the motor design; 2.) perform heat transfer and stability analyses for the chosen design; 3.) aid in the final construction and experimental tests at the Euclid Laboratory; 4.) analyze the experimental data produced.

\subsection{Progress in FY96}

SNL provided design feedback during the motor design process. Analysis confirmed the adequacy of the design. Various heat transfer and instability issues were investigated that could have inhibited steady operation of the motor. SNL's analysis resulted in significant design modifications. The motor performed well during initial testing. However, the heat leaks were larger than expected due to vacuum leaks. Sandia aided in the interpretation of the experimental data and helped determined the specific causes of the heat leaks. On June 20, 1996 a peak operating power of 281 HP was obtained which improved upon our world record for a superconducting motor. A paper was presented and published to disseminate our lessons learned and progress to date: R. F. Schiferl, B. X. Zhang, D. I. Driscoll, B. A. Shoykhet and R. C. Dykhuizen, Development Status of a 125 HP Superconducting Motor, Cryogenic Engineering Conference and International Cryogenic Materials Conference, Columbus, $\mathrm{OH}$, July 18, 1995. These results also appeared in Vol. 42, Advances in Cryogenic Engineering Materials, Plenum Press, NY, 1996. 


\subsection{Future Work}

Reliance Electric has been awarded a Phase II continuation in the SPI program. In Phase II, 1000 and 5000 HP motors will be designed and built. In these larger designs, the coolant will be recycled. Recycling the coolant will require the use of a more complex rotating coupler. Since heat leaks near the coupler region were a problem in Phase I, our understanding of this region will have to be improved. Also, Phase II will include development of cryogenic coolers optimized for HTS motor application. Sandia will be intimately involved in the design of the cooling system for Phase II in much the same manner as Sandia's involvement in Phase I. This involvement will start at the initial design phase. Phase I has demonstrated that a good design results in minimal problems during testing. In phase II, Sandia will also conduct experimental tests of motor components. One set of experimental tests will examine the thermal contact resistance of prototype bolted joints. In the phase II design, the coils will be installed in the vacuum space of the motor, and the heat will have to be removed via conduction through a bolted joint. Sandia will also evaluate the outgassing of the coils and other materials that will be in the vacuum space. Use of novel composite materials in the vacuum space will require testing to determine their outgassing characteristics. 
Dr. James Daley

EE-14, U. S. Dept. of Energy

Forrestal Building

1000 Independence Avenue, SW

Washington, DC 20585

Dr. Christine Platt

CE-32, U. S. Department of Energy

Forrestal Building

1000 Independence Avenue, SW

Washington, DC 20585

Dr. Richard Blaugher

NREL

Branch 210, Location 16/3

1617 Cole Blvd.

Golden, CO 80401

Dr. R. A. Hawsey

Oak Ridge National Laboratory

Superconducting Teclinology Program

P.O. Box 2008

Oak Ridge, TN $37831-6040$

Dr. David O. Welch

Brookliaven National Laboratory

Building 480

Upton, NY 11973

Mr. J. Badin

Energetics

7164 Gateway Drive

Columbia, MD 21046

Mr. D. Driscoll

Reliance Electric

24701 Euclid Avenue

Cleveland. $\mathrm{OH} 44117$

Dr. Pradeep Haldar

Intermagnetics General Corporation

P.O. Box 461

450 Old Nisknyina Rd.

Latham, NY 12110-0461
Mr. Chris Kang

EE-14, U.S. Dept. of Energy

Forrestal Building

1000 Independence Avenue,SW

Washington, DC 20585

Mr. Dan Eckelkamp-Baker

U.S. Department of Energy

KAFB-East, " $\mathrm{H}$ " St. at Pennsylvania

P.O. Box 5400

Albuqquerque, NM 87115

Dr. Nancy Levoy

Nuclear Metals, Inc.

2229 Main Street

Concord, MA 01742

Dr. Dean E. Peterson

Los Alamos National Laboratory

MS-K763

P.O. Box 1663

Los Alamos, NM 87545

Dr. Balu Balachandran

Argonne National Laboratory, ET

Building 212

9700 South Cass Avenue

Argonne, IL 60439-4838

Mr. C. Matzdorf

Energetics

7164 Gateway Drive

Columbia, MD 21046

Mr. James R. Gaines, Jr.

Superconductive Components, Inc.

1145 Clesapeake Avenue

Columbus, $\mathrm{OH} 43212$

Dr. V. Selvamanickam

Intermagnetics General Corporation

P.O. Box 461

450 Old Niskayina Rd.

Latham, NY 12110-0461 
MS-0702

D. E. Arvizu

MS-0752

M. L. Tatro

MS-0968

F. D. Chavez

MS-1405

J. A. Voigt

MS-1421

E. B. Stechel

MS-0959

S. Lockwood

MS-0899

Technical Library (5)

Org. 12690 (For DOE/OSTI

MS-0619

Review and Approval Desk (5)

Org. 12690 (for DOE/OSTI)
MS-0835

T. C. Bickel

MS-0609

W. F. Hammetter

MS-1405

D. Lamppa

MS-1421

E. L. Venturini

MS-0835

R. Dykhuizen

MS-0613

E. P. Roth (5)

MS-9018

Central Technical Files

Org. 8940-2 